University of Wollongong

Research Online

Faculty of Social Sciences - Papers (Archive) Faculty of Arts, Social Sciences \& Humanities

$1-1-2018$

Prestimulus delta and theta contributions to equiprobable Go/NoGo processing in healthy ageing

Frances M. De Blasio

University of Wollongong, francesd@uow.edu.au

Robert J. Barry

University of Wollongong, rbarry@uow.edu.au

Follow this and additional works at: https://ro.uow.edu.au/sspapers

Part of the Education Commons, and the Social and Behavioral Sciences Commons

Research Online is the open access institutional repository for the University of Wollongong. For further information contact the UOW Library: research-pubs@uow.edu.au 


\title{
Prestimulus delta and theta contributions to equiprobable Go/NoGo processing in healthy ageing
}

\author{
Abstract \\ 2018 Elsevier B.V. Ongoing EEG activity contributes to ERP outcomes of stimulus processing, and each of \\ these measures is known to undergo (sometimes significant) age-related change. Variation in their \\ relationship across the life-span may thus elucidate mechanisms of normal and pathological ageing. This \\ study assessed the relationships between low-frequency EEG prestimulus brain states, the ERP, and \\ behavioural outcomes in a simple equiprobable auditory Go/NoGo paradigm, comparing these for 20 \\ young (Mage= 20.4 years) and 20 healthy older (Mage= 68.2 years) adults. Prestimulus delta and theta \\ amplitudes were separately assessed; these were each dominant across the midline region, and reduced \\ in the older adults. For each band, (within-subjects) trials were sorted into ten increasing prestimulus EEG \\ levels for which separate ERPs were derived. The set of ten ERPs for each band-sort was then quantified \\ by PCA, independently for each group (young, older adults). Four components were primarily assessed \\ (P1, N1-1, P2/N2b complex, and P3), with each showing age-related change. Mean RT was comparable, \\ but intra-individual RT variability increased in older adults. Prestimulus delta and theta each generally \\ modulated component positivity, indicating broad influence on task processing. Prestimulus delta was \\ primarily associated with the early sensory processes, and theta more with the later stimulus-specific \\ processes; prestimulus theta also inversely modulated intra-individual RT variability across the groups. \\ These prestimulus EEG-ERP dynamics were consistent between the young and older adults in each band \\ for all components except the P2/N2b, suggesting that across the lifespan, Go/NoGo categorisation is \\ differentially affected by prestimulus delta and theta.

\section{Disciplines} \\ Education | Social and Behavioral Sciences

\section{Publication Details} \\ De Blasio, F. \& Barry, R. (2018). Prestimulus delta and theta contributions to equiprobable Go/NoGo \\ processing in healthy ageing. International Journal of Psychophysiology, 130 40-52.
}


Prestimulus delta and theta contributions to equiprobable Go/NoGo processing in healthy ageing

Frances M. De Blasio* and Robert J. Barry

Brain \& Behaviour Research Institute and School of Psychology, University of Wollongong, Wollongong NSW 2522, Australia

*Corresponding author

Email: francesd@uow.edu.au

Phone: +61242215547

Fax: +61242214421

Address: School of Psychology, University of Wollongong, Wollongong NSW 2522, Australia 


\title{
Highlights
}

- Prestimulus low-frequency EEG was midline dominant and reduced in the older group

- Similar ERP sequence found between groups; older showed typical age-related change

- Prestimulus low-frequency EEG generally modulated ERP component positivity

- Prestimulus theta modulated intra-individual RT variability, but not mean RT

- Age-related change in low-frequency EEG-ERP relationships in PN, P2/N2b, SW, and LP

\begin{abstract}
Ongoing EEG activity contributes to ERP outcomes of stimulus processing, and each of these measures is known to undergo (sometimes significant) age-related change. Variation in their relationship across the life-span may thus elucidate mechanisms of normal and pathological ageing. This study assessed the relationships between low-frequency EEG prestimulus brain states, the ERP, and behavioural outcomes in a simple equiprobable auditory Go/NoGo paradigm, comparing these for 20 young ( $M_{\text {age }}=20.4$ years) and 20 healthy older ( $M_{\text {age }}=68.2$ years) adults. Prestimulus delta and theta amplitudes were separately assessed; these were each dominant across the midline region, and reduced in the older adults. For each band, (within-subjects) trials were sorted into ten increasing prestimulus EEG levels for which separate ERPs were derived. The set of ten ERPs for each band-sort was then quantified by PCA, independently for each group (young, older adults). Four components were primarily assessed (P1, N1-1, P2/N2b complex, and P3), with each showing age-related change. Mean RT was comparable, but intra-individual RT variability increased in older adults. Prestimulus delta and theta each generally modulated component positivity, indicating broad influence on task processing. Prestimulus delta was primarily associated with the early sensory processes, and theta more with the later stimulus-specific processes; prestimulus theta also inversely modulated intra-individual RT variability across the groups. These prestimulus EEG-ERP dynamics were consistent between the young and older adults in each band for all components except the $\mathrm{P} 2 / \mathrm{N} 2 \mathrm{~b}$, suggesting that across the lifespan, Go/NoGo categorisation is differentially affected by prestimulus delta and theta.
\end{abstract}

Keywords: EEG/ERP dynamics; Delta; Theta; Healthy ageing; Principal Components Analysis (PCA); Auditory Go/NoGo 


\section{Introduction}

It is now well established that ongoing electroencephalographic (EEG) activity influences eventrelated potential (ERP) outcomes, although the exact nature and mechanism/s of such contributions remain open to debate (e.g., Barry, 2009; Başar et al., 2001; Fell et al., 2004; Klimesch et al., 2007; Mazaheri and Jensen, 2008; Mazaheri and Picton, 2005; Sauseng et a1., 2007; van Dijk et al., 2010). Interestingly, while the vast EEG and ERP literatures each report significant age-related change, comparatively little is known about the consistency of the relationship between these measures in the context of ageing. An understanding of normative age-related EEG-ERP integrity could inform clinical practice and aid in the early identification of cognitive dysfunction and/or decline. The present study therefore sought to compare the dynamic EEG-ERP relationships in young and well-functioning older adults to assess their stability in healthy ageing.

Low frequency delta and theta band EEG activity have been proposed as possible neurophysiological markers of subclinical cognitive dysfunction or decline (Babiloni et al., 2006; Cummins and Finnigan, 2007; Güntekin and Başar, 2016; Yener et al., 2016), hence this investigation focused on activity in these bands. Healthy ageing is typically associated with diminished (e.g., Babiloni et al., 2006; Barry and De Blasio, 2017; Breslau et al., 1989; Cummins and Finnigan, 2007; Duffy et al., 1984; Emek-Savaş et al., 2016; Polich, 1997a,b; Vysata et al., 2012), and more temporally distributed (e.g., Breslau et al., 1989; Klass and Brenner, 1995) activity in these low frequency bands, but their dominant midline topography is reported to be preserved (e.g., Barry and De Blasio, 2017; Breslau et al., 1989; Emek-Savaş et al., 2016).

Although ERP component measures (latency, amplitude) are each sensitive to age-related change, component amplitudes are the focus of the current investigation. Healthy ageing is generally associated with minimal change in P1 and N1 ERP component amplitudes (e.g., Čeponienè et al., 2008; Ford et al., 1979; Yordanova et al., 2004), with inconsistent effects in P2 (increase: Čeponienè et al., 2008; Pfefferbaum et al., 1980; vs. decrease: Ford et al., 1979), and with amplitude reductions in N2 (e.g., Barry et al., 2016a; Čeponienè et al., 2008) and P3 amplitudes (e.g., Barry et al., 2016a; Čeponienè et al., 2008; Ford et al., 1979; O'Connell et al., 2012; Polich, 1997a; Steiner et al., 2016; van Dinteren et al., 2014a, 2014b, 2017; Yordanova et al., 2004). P3 topography is also commonly reported to be increased anteriorly, and diminished parietally (e.g., Alperin et al., 2014; Friedman et al., 1997; O'Connell et al., 2012; Pfefferbaum et al., 1980; Steiner et al., 2016; van Dinteren et al., 2014a, 2014b, 2017). The absence of the frontal negative aspect of the classic Slow Wave (SW) has also been noted (Pfefferbaum et al., 1980).

In addition to electrophysiological variation, ageing is commonly associated with changes in behavioural responding. Older adult mean Go reaction time (RT) performance is reported as either comparable (e.g., Čeponienè et al., 2008; Polich, 1997a) or increased (e.g., Falkenstein et al., 2006; Fozard et al., 1994) relative to young adults, and intra-individual Go RT variability (IIV) is consistently reported to increase with age (Dykiert et al., 2012; Fozard et al., 1994; MacDonald et al., 2009; Papenberg, Hämmerer, Müller, Lindenberger, and Li, 2013; Schmiedek et al., 2009). Although these RT measures (mean, IIV) are related (Dykiert et al., 2012; Schmiedek et al., 2009), the latter is thought to provide supplementary insight into cognitive function and is predictive of decline (Dykiert et al., 2012; 
MacDonald et al., 2009), hence it warrants independent investigation.

To date there appears to be a single study assessing EEG-ERP relationships in an ageing context (Polich, 1997a; note that a subset of those findings also appears in a secondary paper: Polich, 1997b). Polich assessed non-task resting midline EEG power in relation to peak-picked auditory and visual Oddball ERP component outcomes in participants who self-identified as physically and mentally healthy. In the delta and theta bands, significant correlations were found between the age-related decline in EEG band power and P3 component amplitude. No effects were reported in the N1, P2, or N2 components, and the associations between resting EEG and Go RT were not assessed.

The present study utilised enhanced methodology to build upon Polich's (1997a) findings. Healthy young and older adults completed an equiprobable auditory Go/NoGo paradigm, and the immediately-prestimulus (cf. non-task resting) delta and theta band amplitudes (cf. power) were assessed for their contributions to both ERP component amplitudes derived using principal components analysis (PCA; cf. peak-picked), and Go behavioural response outcomes (mean, IIV). Prestimulus delta and theta band topographies were expected to be midline dominant, and reduced in older relative to young adults in line with the previously reviewed EEG ageing literature. The statistically confirmed band data were then used to generate average Go and NoGo ERPs for 10 discrete levels of ascending prestimulus EEG band amplitude ${ }^{1}$, and their corresponding Go RT data. PCA-derived ERP components common to the young and older adults were assessed; in this paradigm the expected and well established (Barry and De Blasio, 2013, 2015; Barry et al., 2016a, 2018; Fogarty et al., in press) component sequence was, in latency order: P1, N1-1, Processing Negativity (PN), P2/N2b complex, P3, SW, and Late Positivity (LP). Across the prestimulus EEG band amplitude levels, the typical age-related changes in ERP component amplitude and behavioural response performance were anticipated. Little amplitude variation was expected between the young and older adult P1, N1-1, and PN components, while P2/N2b, P3, SW, and LP amplitude reductions were predicted in the older relative to young adults, along with increased anterior positivity in the P3 and SW components. Mean RT was expected to be delayed in the older relative to young adults, although perhaps not significantly so, and IIV was hypothesised to be significantly increased. In line with prior work mapping the EEG-(peak-picked) ERP and EEG-RT relationships in this paradigm in young adults (De Blasio and Barry, 2013), prestimulus delta level was expected to directly modulate P1, N1, P2, $\mathrm{N} 2$, and $\mathrm{P} 3$ component positivity across Go/NoGo; prestimulus theta was anticipated to directly modulate Go N1, P2, and P3 component negativities, inversely modulate NoGo N1, P2, and N2 component magnitudes, and directly modulate NoGo P3 magnitude; and neither band was expected to modulate mean Go RT across the young and older adults. In line with Polich (1997a), it was further expected that agerelated consistency in these relationships would be restricted to the P3 component.

\footnotetext{
${ }^{1}$ Ten prestimulus EEG band amplitude levels were quantified (cf. two in our prior work; De Blasio \& Barry, 2013) to facilitate a more fine-grained analysis of the linear EEG-ERP relationships, and to improve the cases-to-variables ratio for PCA component quantification (Gorsuch, 1983).
} 
As PCA ERP component derivation disentangles the subcomponents which underlie and combine to form the more traditional peak-picked components (e.g., N1-1 and PN are subcomponents of the N1; Näätänen and Picton, 1987), the direct correspondence between the components derived in each method may be limited. The present study therefore focused on the following PCA derived ERP components (corresponding peak-picked components indicated if differing): P1, N1-1 (N1), P2/N2b (P2 and N2), and P3. In order to promote future research, analyses in the remaining components (PN, SW, and LP) are presented as Supplementary Material.

\section{Methods}

\subsection{Participants}

This study utilised data from the sample of young and older adults assessed in Barry et al. (2016a). Twenty university students, aged $18.8-25.6$ years $(M=20.4, S D=1.6)$, and 20 gender matched healthy older adults, aged $59.8-74.8$ years $(M=68.2, S D=4.5)$, participated voluntarily. The young adults were recruited from the University of Wollongong and received partial credit towards their undergraduate Psychology course. The older adults were recruited from a local resort-style retirement village and received a cash payment of AU\$40 for their time; they were living unassisted and identified themselves as generally healthy. Each group (young, older) had 15 females (5 males) and all participants were right-handed and claimed normal hearing, normal or corrected vision, and caffeine and tobacco abstinence for a minimum of 2.5 hours prior to testing. Participants were screened for a history of seizures, psychiatric illness, recent psychoactive drug use, and prior severe head trauma resulting in long term impairment. The older adults were additionally screened for cognitive impairment using the Rowland Universal Dementia Assessment Scale (RUDAS; Story et al., 2004), and supplied a list of current medication including dosage and consumption interval. Study inclusion was contingent upon the older adults achieving a RUDAS score greater than the threshold for possible cognitive impairment (i.e., 22 out of 30); all participants met this criterion (scores ranged from 26 to $30 ; M=28.0, S D=1.5$ ). Ethics approval was obtained from the joint South Eastern Sydney/Illawarra Area Health Service and University of Wollongong Health and Medical Human Research Ethics Committee, and written informed consent was obtained from each participant.

\subsection{Physiological Recording}

Continuous EEG data between 0.15 and $30 \mathrm{~Hz}$ were sampled at $1000 \mathrm{~Hz}$ using a Neuroscan Synamps 2 amplifier and Neuroscan Acquire Software (Compumedics, Version 4.3.1). Electrode caps fitted with 19 tin electrodes (Fp1, Fp2, F7, F3, Fz, F4, F8, T7, C3, Cz, C4, T8, P7, P3, Pz, P4, P8, O1, $\mathrm{O} 2)$ were used. Electro-oculogram (EOG) data were also recorded using tin electrodes placed above and below the left eye (vertical EOG), and beyond the outer canthus of each eye (horizontal EOG). EEG data were referenced to the left ear, and right ear data were recorded as a separate channel for later digital rereferencing. All impedances were below $10 \mathrm{~K} \Omega$, and care was taken to balance the ear electrodes. EEG and EOG data were recorded with a gain of 500 and saved for off-line analysis. 


\subsection{Task and Procedure}

A brief two-part EOG calibration task was presented. First, a visual stimulus (a small red square) was shown at various locations on a computer screen and participants were required to shift their gaze to the stimulus without moving their head. This yielded a total of 40 consecutive vertical (i.e., stimulus alternating middle top/bottom), and 40 consecutive horizontal (i.e., stimulus alternating central left/right) eye movements. Second, the stimulus was presented at the centre of the screen, and participants were required to blink each time it changed colour, producing a total of 40 eye-blinks.

The experiment proper utilised an equiprobable auditory Go/NoGo paradigm. As reported in Barry et al. (2016a), each block consisted of 150 tone stimuli (75 at 1000 and 75 at $1500 \mathrm{~Hz}$, each $80 \mathrm{~ms}$ duration including $15 \mathrm{~ms}$ rise/fall times) presented binaurally at $60 \mathrm{~dB}$ SPL (young group) and $70 \mathrm{~dB}$ (older group) via circumaural stereo headphones (Sony MDR-V700). Note that, although the stimulus intensity differed between the groups, it was consistent within-group (i.e., across the 1000 and $1500 \mathrm{~Hz}$ stimuli). The increased stimulus intensity for the older group was implemented to reduce the likelihood of audibility deficits influencing the processing outcomes in this sample (Fulton et al., 2015; Grassi and Borella, 2013), and all participants reported being able to hear and discriminate between the 1000 and $1500 \mathrm{~Hz}$ tones prior to the experimental block presentations; this was the only paradigmatic variation between the participant groups. Stimuli were delivered with a fixed 1,100 ms stimulus onset asynchrony (SOA) in a randomised order unique to each participant and block. Participants were instructed to fixate a small cross presented at the centre of a computer monitor, and to respond to the Go tone with their dominant (right) hand by pressing the trigger button of a hand-held game controller (Logitech Precision Gamepad) as quickly and accurately as possible. Each block was approximately 3 minutes long, the frequency of the Go tone alternated between consecutive blocks, and the Go frequency of the first block was counterbalanced across participants in each group (young, older).

Each participant read an information sheet and completed consent and screening forms upon arrival. The recording equipment was fitted and the participants were seated approximately $1 \mathrm{~m}$ from a 19" LCD computer monitor. The EOG calibration task was completed first, and then each participant completed four blocks of the equiprobable Go/NoGo paradigm. Brief rest periods ( $\sim 2-3$ minutes) were interspersed between the stimulus block presentations to prevent fatigue, producing a total testing time less than 30 minutes.

\subsection{Data Quantification}

A schematic of the quantification methodology is provided in the Supplementary Material (section S1). During the pre-processing stage, the continuous EEG data were first EOG corrected using the RAAA Correction Program (Croft and Barry, 2000). Neuroscan Edit software (Compumedics, Version 4.5.1) was then used to digitally re-reference to linked ears, and epoch $(-500$ to $+1,000 \mathrm{~ms})$ the data. Go and NoGo epochs were extracted separately, but only for those with correct responses (Go: response made in the within-subject $M \pm 2 S D$ RT window; NoGo: no response within the $1,100 \mathrm{~ms}$ SOA). The epochs were baselined ( -100 to $0 \mathrm{~ms}$ ), and those with activity exceeding $\pm 100 \mu \mathrm{V}$ at any of the 19 scalp sites (i.e., residual artefact) were automatically detected and removed. Using EEGLAB (Version 9.0.8.6b; Delorme and Makeig, 2004), the accepted artefact-corrected scalp EEG was imported into MATLAB (The Mathworks; Version 8.0.0.783, R2012b). The remainder of the processing was 
completed in MATLAB using custom scripts that, unless otherwise stated, processed the data separately for each participant (young, older) and stimulus (Go, NoGo)

To quantify the prestimulus EEG band amplitudes, prestimulus epochs (-500 to $0 \mathrm{~ms}$ ) were extracted and DC corrected (i.e., baselined across their duration). At each scalp site, individual epoch data were multiplied by a 500 point $10 \%$ ( 25 point rise, 25 point fall) Hanning window and zero-padded to 2,000 points before being subjected to a Discrete Fourier Transform (DFT; $\Delta \mathrm{f}=0.5 \mathrm{~Hz}$ ). Corrections were applied for the use of the Hanning window and zero-padding; the complex DFT output was multiplied by a factor of 1.05 (window length/sum) to correct for the former, and then multiplied by the pad-ratio (4) to correct for the latter, before the DFT amplitudes were extracted for each $0.5 \mathrm{~Hz}$ narrow frequency bin. All subsequent processing was conducted separately for each assessed band. Prestimulus EEG band amplitudes were computed as the sum of the DFT amplitudes in the contributing frequencies (delta: $0.5-3.5 \mathrm{~Hz}$; theta: $4.0-7.5 \mathrm{~Hz}$ ) for each scalp site and epoch. Separate topographic analyses of the within-subject mean prestimulus EEG band amplitude and intra-individual amplitude variability (standard deviation across epochs) were used to identify the topographic region of interest (see section 2.5.1. for further detail). The mean prestimulus EEG band amplitude across the identified region of interest was then computed for each Go and NoGo epoch and stored for use in ERP quantification. It should be noted that ERP components that peaked at or after $600 \mathrm{~ms}$ (such as the LP) directly overlapped the prestimulus period of the subsequent trial due to the fixed $1,100 \mathrm{~ms}$ SOA used in this paradigm. In order to rule out contributions from the ongoing phase-locked activity to the subsequent prestimulus EEG period, the spectra and band amplitude data were similarly derived for the mean (across trials vs. individual trials) prestimulus epochs. These data are presented in the Supplementary Material (section S2).

ERP quantification involved the following procedure, applied separately for each assessed band (delta, theta). First, the full EEG epochs $(-500$ to $+1,000 \mathrm{~ms})$ were retrieved and cut ( -100 to $+1,000 \mathrm{~ms})$, and the previously computed mean prestimulus EEG band amplitude in the identified region of interest was used to sort the EEG epochs at all 19 scalp sites. The necessary number of Go and NoGo epochs were then dropped from their respective sorted epoch sets to ensure within-subject epoch counts evenly divisible by 10. The dropped epochs were selected in a distributed fashion to avoid biasing the spread of prestimulus EEG band amplitude values in the retained epochs (i.e., rejecting $x$ epochs spaced approximately [epoch count/(x+1)] apart). The sorted epochs that remained were sub-divided (withinsubjects) into 10 prestimulus EEG band levels of no less than 20 epochs each; refer to Supplementary Material section S3 for information regarding the number of epochs involved in each quantification step (i.e., total accepted, removed following sorting, contributing to each ERP). Average ERPs were derived for each prestimulus EEG band level, and their corresponding mean prestimulus EEG band amplitudes were recorded for later analysis. In Go, mean RT and IIV (standard deviation across contributing epochs $^{2}$ ) were additionally computed. The prestimulus EEG band level ERPs were then down-sampled to $500 \mathrm{~Hz}$ and their component amplitudes quantified using the ERP PCA toolkit (v. 2.23; Dien, 2010) and

\footnotetext{
${ }^{2}$ The raw intra-individual RT variability measure was assessed here as there is currently no consensus regarding the application of a mean correction (Dykiert et al., 2012), and the assumptions underlying such a correction have been invalidated (Schmiedek et al., 2009).
} 
Varimax4M rotation (Kayser and Tenke, 2003; http://psychophysiology.cpmc.columbia.edu/software/). Four temporal PCAs were conducted: one for each sorting band (delta, theta), for each group (young, older adults), and all included Go and NoGo data. Each PCA had 7,600 cases (20 participants $\times 2$ stimuli $\times 10$ prestimulus EEG band levels $\times 19$ sites) and 550 variables/time-points, used the covariance matrix with Kaiser normalisation, and all 550 factors underwent unrestricted Varimax rotation following Kayser and Tenke's (2003) procedure. For each group (young, older adults), factors were identified as ERP components based on their correspondence with those identified in Barry et al. (2016a) in terms of their latency, polarity, and peak amplitude topography. PCA components were considered for identification in ascending order of their data variance accounted for, and identified independently for each PCA. For each identified component common to the young and older groups, the peak component amplitudes at the nine inner electrodes (F3, Fz, F4, C3, Cz, C4, P3, Pz, P4) were derived using Dien's (2010) toolkit and exported for analysis.

\subsection{Statistical Analysis}

Mixed-model repeated measures MANOVA was the primary statistical test employed in this study. MANOVA was selected over the more traditional ANOVA as repeated measures data are known to violate the assumption of sphericity, and the MANOVA procedure with planned contrasts is free from this constraint (O’Brien and Kaiser, 1985; Vasey and Thayer, 1987). MANOVA is a versatile analysis that can be easily and appropriately applied to univariate data, and thus offers an efficient and precise tool for repeated measures analysis without the need for degree of freedom (i.e., Greenhouse-Geisser) corrections (Picton et al., 2000). SPSS Statistics (version 21) syntax was used to conduct each MANOVA in this study.

\subsubsection{Prestimulus Delta and Theta Band Amplitudes}

Prestimulus EEG band topography and age-related change were assessed for each EEG band (delta, theta), and prestimulus EEG band amplitude measure (mean, intra-individual variability). Group (young, older adults) served as the between-subjects factor in each MANOVA, and the Sagittal (frontal, central, parietal) and Lateral (left, midline, right) topographic dimensions were the within-subjects factors. Prestimulus EEG band topography was examined using planned orthogonal contrasts. In the sagittal plane, the frontal (F: F3, Fz, F4) and parietal (P: P3, Pz, P4) regions were compared, and also the central $(\mathrm{C}: \mathrm{C} 3, \mathrm{Cz}, \mathrm{C} 4)$ region versus the fronto-parietal mean $(\mathrm{F} / \mathrm{P}: \mathrm{F} 3, \mathrm{Fz}, \mathrm{F} 4, \mathrm{P} 3, \mathrm{Pz}, \mathrm{P} 4)$. In the lateral plane, the left (L: F3, C3, P3) and right (R: F4, C4, P4) hemispheres were compared, and also the midline (M: Fz, Cz, Pz) region versus the hemispheric mean (L/R: F3, C3, P3, F4, C4, P4). Given the randomised presentation order in this equiprobable task, prestimulus EEG band activity was not expected to vary by stimulus condition; these analyses were therefore conducted across Go/NoGo.

Topographic outcomes identified the region of interest for each band, the region with maximal or most variable band activity across Go/NoGo and Group. Mean Go and NoGo band amplitudes in the region of interest were used to sort and subdivide accepted epochs in their respective condition (withinsubjects), yielding the 10 Go and 10 NoGo ERPs with ascending prestimulus EEG band amplitudes (per participant and band) facilitating the examination of prestimulus EEG level effects in each assessed band. The fit of a linear trend to the 10 mean (across-participant) prestimulus EEG band amplitudes, one for each of the prestimulus EEG band level ERPs, was used to validate this prestimulus EEG band amplitude 
sorting procedure. Within-subject prestimulus EEG band amplitude covariation was used to examine the appropriate separation of prestimulus EEG activity in each assessed band; that is, the corresponding mean prestimulus EEG band amplitudes were derived for the non-sorting band, and these were tested for their covariance with the sorting-band amplitudes across the 10 prestimulus EEG band level ERPs. These analyses were conducted independently for each band (delta, theta), group (young, older adults), and stimulus (Go, NoGo).

\subsubsection{ERP Component Amplitudes and Behavioural Response Outcomes}

Only those PCA derived ERP components common to the young and older adult groups and consistent with those reported in Barry et al. (2016a) were analysed; see Supplementary Material (section S4) for further information. Peak amplitude topography and the effects of stimulus condition, age-related change, and prestimulus EEG band level were analysed for each assessed component derived in each prestimulus EEG band sorting condition (delta, theta). Each MANOVA had Group (young, older adults) as the between-subjects factor, and the Sagittal and Lateral topographic dimensions (as defined in section 2.5.1.), Stimulus (Go, NoGo), and Level (10 prestimulus EEG band levels, L01 to L10) as the withinsubjects factors. Component topography was examined using the planned orthogonal contrasts described in section 2.5.1., and linear effects of Level were assessed with a planned contrast.

Go RT was similarly examined as a function of age-group and prestimulus EEG band level for each sorting band (delta, theta), and response measure (mean, IIV).

\subsubsection{Consideration of Multiple Testing}

All contrasts were planned a priori and there were fewer contrasts than degrees of freedom for effect, so Bonferroni-type $\alpha$ adjustments were unnecessary (Tabachnick and Fidell, 2013). The assessment of each measure (i.e., several ERP components, behavioural outcomes) can be considered an independent experiment. The probability of Type 1 errors is independent of the number of experiments (i.e., $\alpha=.05$ ), while their frequency is proportionate (i.e., 1 in 10 tests, 10 in 100 tests); this cannot be controlled using Bonferroni-type $\alpha$ adjustments (Howell, 1997). However, Benjamini and Hochberg's (1995) False Discovery Rate (FDR) control procedure was applied to correct for the multiple testing of the same dependent data for two prestimulus EEG bands (delta, theta). For each contrast, the corresponding $p$ values in each prestimulus EEG band sorting condition (delta, theta) had to meet the adjusted $\alpha$ value, which incremented in a stepwise fashion. That is, the most significant $p$ value had to meet $\alpha<.025$, and the least $\alpha<.050$, to be retained; for more information see Benjamini and Hochberg (1995). Statistical reporting is limited to the effects that met this criterion, and these are presented with their initial $p$ value (cf. adjusted $\alpha$ threshold). Each $F$ test had $(1,38)$ degrees of freedom.

\section{Results}

\subsection{Prestimulus Delta and Theta Band Amplitudes}

\subsubsection{Spectral Amplitude, Band Topography, \& Age-related Change}

Figure 1 illustrates the prestimulus low-frequency EEG spectral amplitudes (upper panel) and associated prestimulus delta and theta topographic amplitude distributions (lower panel) for the young and older adult groups. Table 1 displays the corresponding topographic and Group statistics for each measure (mean amplitude, amplitude variability). 
Grand mean (GM) prestimulus delta amplitude and amplitude variability (IIV) were increased in the right hemisphere, at the vertex, and were maximal across the midline. Mean delta amplitude was also increased in the central region and frontal hemispheres across the groups. In the older relative to young adults, prestimulus delta amplitude and amplitude variability were globally reduced (across sites), and more so in the parietal region.

Grand mean prestimulus theta amplitude and amplitude variability were increased at the vertex, and were maximal in the midline; the parietal elevation apparent in Figure 1 failed to survive FDR correction ( $p \geq .041$; adjusted $\alpha=.025$ ). Significant global reductions in prestimulus theta amplitude and amplitude variability were found in the older relative to young adult group, as were reductions in this band's prominent midline topography.

Table 1. Prestimulus EEG band amplitude topography and Group (young, older) effects.

\begin{tabular}{|c|c|c|c|c|c|c|c|c|c|c|c|c|}
\hline \multirow[b]{3}{*}{ Effect } & \multicolumn{6}{|c|}{ Prestimulus delta } & \multicolumn{6}{|c|}{ Prestimulus theta } \\
\hline & \multicolumn{3}{|c|}{ Mean } & \multicolumn{3}{|c|}{ IIV } & \multicolumn{3}{|c|}{ Mean } & \multicolumn{3}{|c|}{ IIV } \\
\hline & $F$ & $p$ & $\eta_{\mathrm{p}}^{2}$ & $F$ & $p$ & $\eta_{\mathrm{p}}^{2}$ & $F$ & $p$ & $\eta_{p}^{2}$ & $F$ & $p$ & $\eta_{p}^{2}$ \\
\hline $\mathrm{C}>\mathrm{F} / \mathrm{P}$ & 6.01 & .019 & .14 & & & & & & & & & \\
\hline $\mathrm{L}<\mathrm{R}$ & 11.55 & .002 & .23 & 6.67 & .014 & .15 & & & & & & \\
\hline $\mathrm{M}>\mathrm{L} / \mathrm{R}$ & 130.96 & $<.001$ & .78 & 110.01 & $<.001$ & .74 & 121.96 & $<.001$ & .76 & 76.23 & $<.001$ & .67 \\
\hline $\mathrm{F}>\mathrm{P} \times \mathrm{M}<\mathrm{L} / \mathrm{R}$ & 5.88 & .020 & .13 & & & & & & & & & \\
\hline $\mathrm{C}>\mathrm{F} / \mathrm{P} \times \mathrm{M}>\mathrm{L} / \mathrm{R}$ & 9.42 & .004 & .20 & 9.65 & .004 & .20 & 20.32 & $<.001$ & .35 & 6.30 & .016 & .14 \\
\hline $\mathrm{Y}>\mathrm{O}$ & 28.74 & $<.001$ & .43 & 7.30 & .010 & .16 & 21.54 & $<.001$ & .36 & 13.46 & .001 & .26 \\
\hline $\mathrm{Y}>\mathrm{O} \times \mathrm{F}<\mathrm{P}$ & 9.43 & .004 & .20 & 5.53 & .024 & .13 & & & & & & \\
\hline $\mathrm{Y}>\mathrm{O} \times \mathrm{M}>\mathrm{L} / \mathrm{R}$ & & & & & & & 6.30 & .016 & .14 & 7.66 & .009 & .17 \\
\hline
\end{tabular}

Notes: IIV = intra-individual amplitude variability; $\mathrm{C}=$ central; $\mathrm{F} / \mathrm{P}=$ fronto-parietal mean; $\mathrm{L}=$ left hemisphere; $\mathrm{R}=$ right hemisphere; $\mathrm{M}=$ midline; $\mathrm{L} / \mathrm{R}=$ hemispheric mean; $\mathrm{F}=$ frontal; $\mathrm{P}=$ parietal; $\mathrm{Y}=$ young adult group; $\mathrm{O}=$ older adult group. 

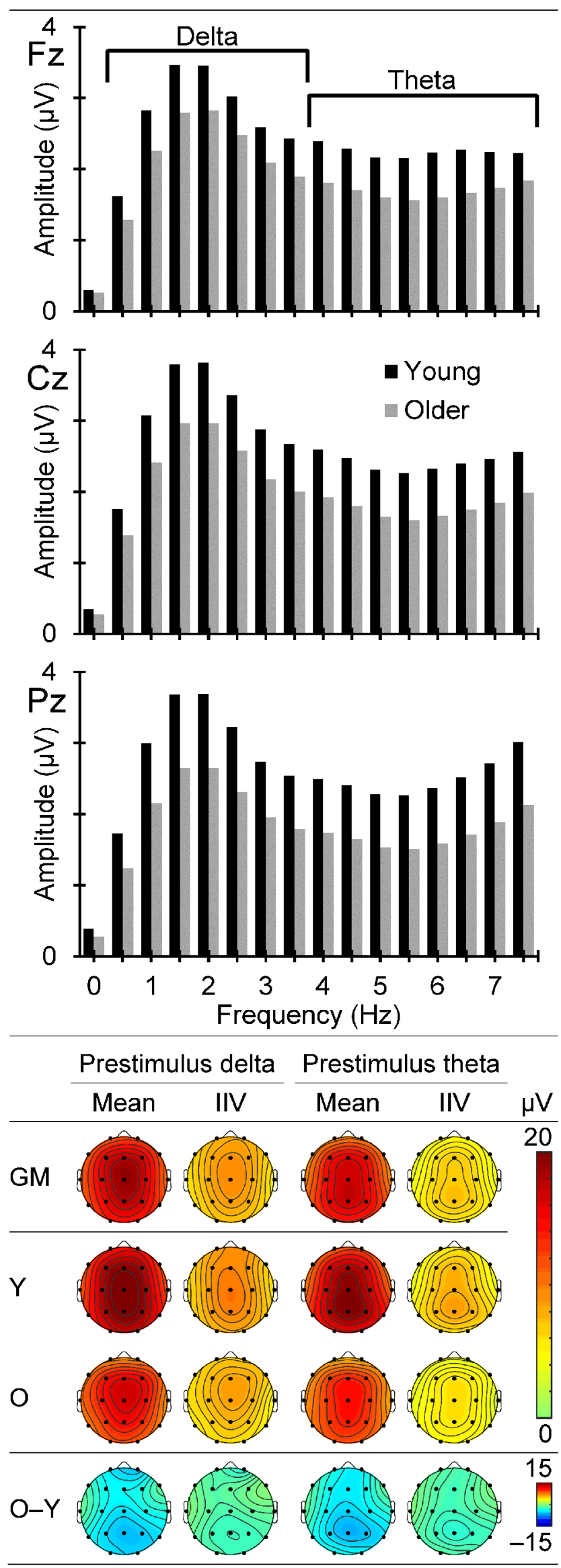

Figure 1. Prestimulus EEG amplitudes. Upper panel: Grand mean midline lowfrequency prestimulus spectra of the young and older adult groups derived from individual Go and NoGo epochs, then averaged within- then across-subjects and conditions. Note the prominent peak delta frequency of $\sim 1.5-2 \mathrm{~Hz}$ in both groups, and the less obvious frontal theta peak at $\sim 6.5 \mathrm{~Hz}$. Lower panel: Corresponding prestimulus delta and theta band amplitude topographies for the grand mean across all participants (GM), separate young $(\mathrm{Y})$ and older (O) adult groups, and the older relative to young adult difference $(\mathrm{O}-\mathrm{Y})$. The Mean (across-subject) band amplitude, and mean within-subject IntraIndividual amplitude Variability (IIV) measures are each presented. A colour version of this figure is available online. 


\subsubsection{Validation of the Prestimulus EEG Band Amplitude Levels}

Separately for the delta and theta bands, mean prestimulus EEG band amplitude in the midline region was used to sort and sub-divide epochs into the 10 prestimulus EEG band amplitude levels (within-subjects) from which the ERPs were derived. Grand mean prestimulus EEG band amplitudes increased linearly across the 10 prestimulus EEG band amplitude levels (L01 to L10) for each sort band (delta, theta); the significant linear trends in each Group (young, older adults) and Stimulus (Go, NoGo) accounted for no less than $91.0 \%$ of the variance (in the older adults, Go prestimulus delta sort) as reported in Table 2. Prestimulus delta and theta band amplitude covariation across the 10 prestimulus EEG band amplitude levels is also presented in Table 2 for each sort condition. These scores and equations suggest minimal amplitude covariation between the bands for the prestimulus delta sorted levels, and although the covariance scores were increased in the prestimulus theta sort, and particularly so in the older adults, the covariance equations show only a small increase in band covariance.

Table 2. Mean prestimulus EEG band amplitude level linearity (L01 to L10), and prestimulus EEG band amplitude covariance in each sort condition.

\begin{tabular}{|c|c|c|c|c|c|c|c|c|c|}
\hline & \multicolumn{4}{|c|}{ Prestimulus delta sort } & \multicolumn{4}{|c|}{ Prestimulus theta sort } \\
\hline & & $\%$ Var. & $r(8)$ & $\operatorname{Cov}(\delta, \theta)$ & Covariance Eqn. & $\%$ Var. & $r(8)$ & $\operatorname{Cov}(\theta, \delta)$ & Covariance Eqn. \\
\hline \multirow[t]{2}{*}{ Young } & Go & 93.1 & .96 & $.20(.06)$ & $\theta=0.13(\delta)+4.06$ & 92.2 & .96 & $.31(.11)$ & $\delta=0.17(\theta)+4.18$ \\
\hline & NG & 92.6 & .96 & $.21(.06)$ & $\theta=0.15(\delta)+3.95$ & 92.3 & .96 & $.33(.14)$ & $\delta=0.18(\theta)+4.16$ \\
\hline \multirow[t]{2}{*}{ Older } & Go & 91.0 & 95 & $.23(.08)$ & $\theta=0.14(\delta)+2.71$ & 93.0 & 96 & $.50(.30)$ & $\delta=0.21(\theta)+2.75$ \\
\hline & NG & 92.1 & .96 & $.23(.08)$ & $\theta=0.14(\delta)+2.65$ & 93.2 & .97 & $.53(.34)$ & $\delta=0.22(\theta)+2.70$ \\
\hline
\end{tabular}

Notes: $\%$ Var. $=$ percentage variance accounted for by the linear trend across the 10 prestimulus EEG band levels ( $(\mathrm{O} 01$ to $\mathrm{L} 10)$ in the sorting band; $\operatorname{Cov}()=M(S D)$ across the within-subject covariation scores between prestimulus delta and theta band amplitudes; $\delta=$ delta; $\theta=$ theta; Covariance Eqn . = equation of the linear trend fitted to the 10 prestimulus EEG band level amplitudes in the non-sort band.

All $r$ were significant at $p<.001$ (one-tailed).

\subsection{Age-related Change in ERP Component Amplitude}

Interested readers are referred to the Supplementary Material for information regarding PCA component identification (section S4), grand mean and Go/NoGo component topography (across Group and Level) of each identified component (section S5), and age-related change in the additional ERP components beyond the current investigation (i.e., PN, SW, and the LP; section S6). Figure 2 illustrates age-related change in the ERP waveforms (panel A) and topographic headmaps of the four PCA derived ERP components of interest (panel B); Group statistics are reported in Table 3 for these components. The substantial similarity between the prestimulus delta and theta sort data in Figure 2 and Table 3 reflects the independence of the ageing (cf. prestimulus EEG band level) effects, particularly given the significant overlap in the epochs contributing to each band sort condition (differing by less than $\sim 5 \%$ per participant per stimulus; see Supplementary Materials section S3). 


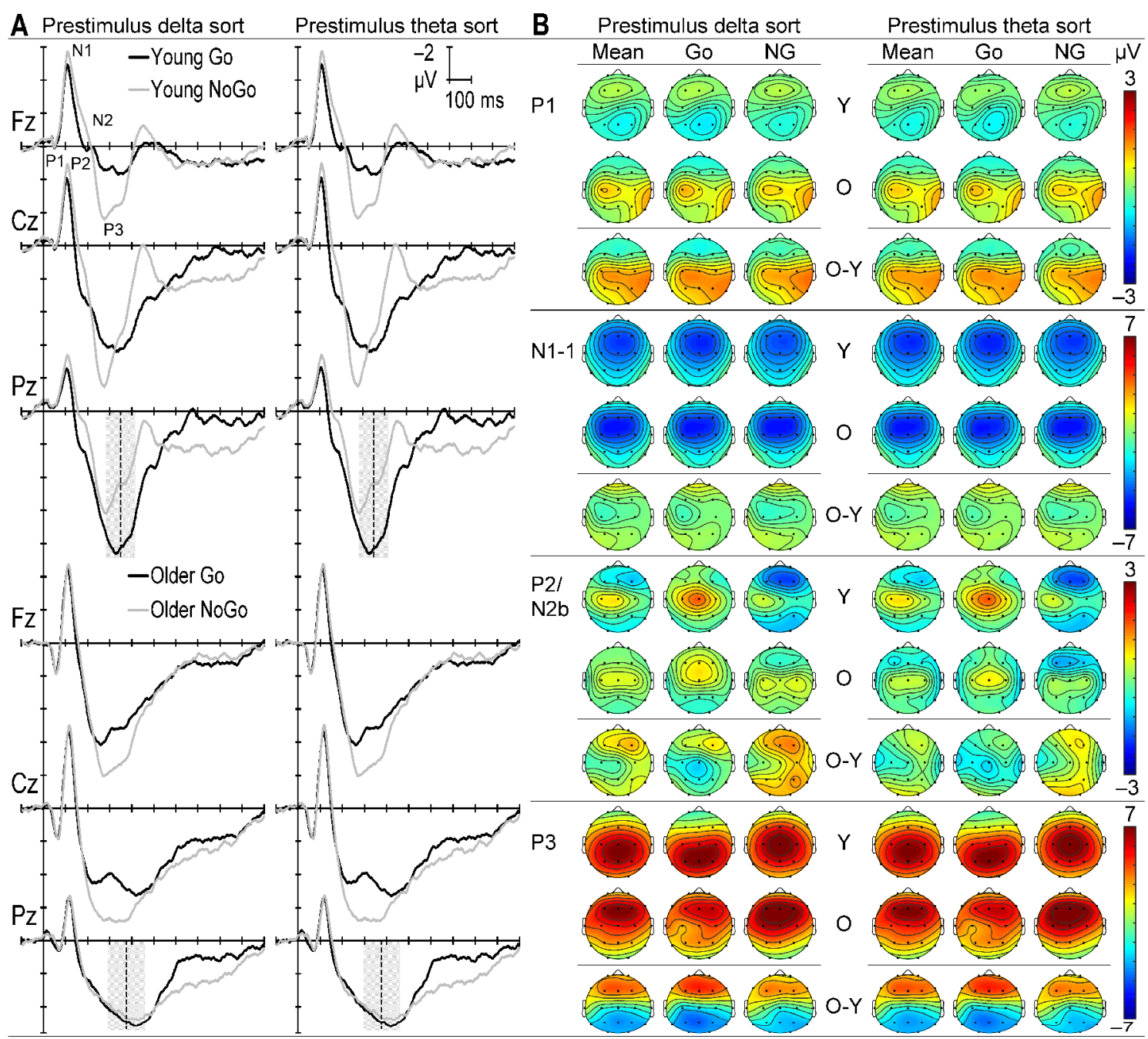

Figure 2. Age-related change in ERP component amplitude. Each panel displays Go and NoGo data, averaged across the 10 prestimulus EEG band Levels to show the independent effects of ageing, for the prestimulus delta (left) and prestimulus theta (right) sort conditions. Panel A: Midline ERPs for the young (top) and older (bottom) adult groups are plotted with a consistent scale for easy comparison; the scale key is presented in the young Fz theta sort plot (top right). The visible ERP component peaks are labelled in the young Fz delta sort plot (top left). Mean Go RT (dashed line) and mean RT intraindividual variability (shading) are indicated for each group and sort condition in the corresponding $\mathrm{Pz}$ plots. Panel B: Topographic headmaps for the assessed PCA derived components. Distributions are presented for the young $(\mathrm{Y})$ and older $(\mathrm{O})$ adults, and their difference (older relative to young; $\mathrm{O}-\mathrm{Y}$ ). This figure is available in colour online. 
Table 3. Group (young, older adult) effects on Go/NoGo processing outcomes.

\begin{tabular}{|c|c|c|c|c|c|c|c|}
\hline \multirow[b]{2}{*}{ Outcome } & \multirow[b]{2}{*}{ Effect } & \multicolumn{3}{|c|}{ Prestimulus delta sort } & \multicolumn{3}{|c|}{ Prestimulus theta sort } \\
\hline & & $F$ & $p$ & $\eta_{\mathrm{p}}^{2}$ & $F$ & $p$ & $\eta_{\mathrm{p}}^{2}$ \\
\hline \multirow[t]{2}{*}{ P1 } & $\mathrm{Y}<\mathrm{O} \times \mathrm{F}<\mathrm{P}$ & 12.27 & .001 & .24 & 10.18 & .003 & .21 \\
\hline & $\mathrm{Y}<\mathrm{O} \times \mathrm{C}>\mathrm{F} / \mathrm{P}$ & 16.07 & $<.001$ & .30 & 14.77 & $<.001$ & .28 \\
\hline \multirow[t]{3}{*}{ N1-1 } & $\mathrm{Y}<\mathrm{O} \times \mathrm{C}>\mathrm{F} / \mathrm{P}$ & 9.45 & .004 & .20 & 9.33 & .004 & .20 \\
\hline & $\mathrm{Y}<\mathrm{O} \times \mathrm{C}>\mathrm{F} / \mathrm{P} \times \mathrm{L}>\mathrm{R}$ & 8.09 & .007 & .18 & 8.16 & .007 & .18 \\
\hline & $\mathrm{Y}<\mathrm{O} \times \mathrm{G}>\mathrm{N} \times \mathrm{C}>\mathrm{F} / \mathrm{P} \times \mathrm{L}>\mathrm{R}$ & 7.59 & .009 & .17 & 6.29 & .017 & .14 \\
\hline \multirow[t]{2}{*}{$\mathrm{P} 2 / \mathrm{N} 2 \mathrm{~b}$} & $\mathrm{Y}>\mathrm{O} \times \mathrm{L}>\mathrm{R}$ & 7.44 & .010 & .16 & 4.99 & .031 & .12 \\
\hline & $\mathrm{Y}>\mathrm{O} \times \mathrm{G}>\mathrm{N}$ & 6.77 & .013 & .15 & & & \\
\hline \multirow[t]{9}{*}{ P3 } & $\mathrm{Y}>\mathrm{O} \times \mathrm{F}<\mathrm{P}$ & 17.78 & $<.001$ & .32 & 17.33 & $<.001$ & .31 \\
\hline & $\mathrm{Y}>\mathrm{O} \times \mathrm{C}>\mathrm{F} / \mathrm{P}$ & 8.50 & .006 & .18 & 8.81 & .005 & .19 \\
\hline & $\mathrm{Y}>\mathrm{O} \times \mathrm{F}<\mathrm{P} \times \mathrm{M}>\mathrm{L} / \mathrm{R}$ & 5.99 & .019 & .14 & 5.19 & .028 & .12 \\
\hline & $\mathrm{Y}>\mathrm{O} \times \mathrm{G}>\mathrm{N} \times \mathrm{F}<\mathrm{P}$ & 7.75 & .008 & .17 & 6.20 & .017 & .14 \\
\hline & $\mathrm{Y}>\mathrm{O} \times \mathrm{G}>\mathrm{N} \times \mathrm{C}>\mathrm{F} / \mathrm{P}$ & 5.74 & .022 & .13 & 4.46 & .041 & .11 \\
\hline & $\mathrm{Y}<\mathrm{O} \times \mathrm{G}>\mathrm{N} \times \mathrm{L}<\mathrm{R}$ & 15.04 & $<.001$ & .28 & 15.38 & $<.001$ & .29 \\
\hline & $\mathrm{Y}>\mathrm{O} \times \mathrm{G}>\mathrm{N} \times \mathrm{F}<\mathrm{P} \times \mathrm{M}>\mathrm{L} / \mathrm{R}$ & 10.97 & .002 & .22 & 9.64 & .004 & .20 \\
\hline & $\mathrm{Y}<\mathrm{O} \times \mathrm{G}>\mathrm{N} \times \mathrm{C}>\mathrm{F} / \mathrm{P} \times \mathrm{L}<\mathrm{R}$ & 5.52 & .024 & .13 & 5.16 & .029 & .12 \\
\hline & $\mathrm{Y}>\mathrm{O} \times \mathrm{G}<\mathrm{N} \times \mathrm{C}>\mathrm{F} / \mathrm{P} \times \mathrm{M}>\mathrm{L} / \mathrm{R}$ & 9.46 & .004 & .20 & 9.27 & .004 & .20 \\
\hline RT (IIV) & $\mathrm{Y}<\mathrm{O}$ & 6.43 & .015 & .14 & 6.16 & .018 & .14 \\
\hline
\end{tabular}

Notes: $\mathrm{Y}=$ young adult; $\mathrm{O}=$ older adult; $\mathrm{F}=$ frontal; $\mathrm{P}=$ parietal; $\mathrm{C}=$ central; $\mathrm{F} / \mathrm{P}=$ fronto-parietal mean; $\mathrm{L}=$ left hemisphere; $\mathrm{R}=$ right hemisphere; $\mathrm{M}=$ midline; $\mathrm{L} / \mathrm{R}=$ hemispheric mean; $\mathrm{G}=\mathrm{Go} ; \mathrm{N}=\mathrm{NoGo}$; RT (IIV) = intra-individual RT variability.

For each prestimulus EEG band sort condition (delta, theta), mean (across Go/NoGo) P1 positivity was enhanced centro-parietally in the older relative to young adults. Older (cf. young) adult N1-1 negativity was enhanced centrally, particularly in the left, and this relative central-left enhancement was greater in Go than NoGo. Across Go/NoGo the relative left hemispheric P2/N2b positivity bias was reduced in the older relative to the young adults, and in the prestimulus delta sort, the enhanced global Go positivity (cf. NoGo negativity) was also smaller in the older than young. In contrast to the young P3, the older P3 showed centro-parietal and parietal-midline reductions, and each were greater in Go than NoGo. The older adults also showed relative P3 enhancements in the right hemisphere for Go compared to NoGo, particularly in the central region, and a vertex reduction in NoGo relative to the young. 


\subsection{Age-related Change in Behavioural Response}

Mean RT and mean IIV (across Level) are each indicated in Figure 2 (see Pz plots, panel A) for each Group (young, older adult) and prestimulus EEG band sort condition (delta, theta). Mean RTs were nonsignificantly delayed in the older relative to young adults for each prestimulus EEG band sort condition (both $p$ $\geq .160$ ), and their IIV significantly increased; refer to Table 3 for the associated statistics.

\subsection{Linear Effects of Prestimulus EEG Band Level}

Figure 3 illustrates the effect of prestimulus delta and prestimulus theta band amplitude level on the mean (across Go/NoGo) ERP component waveforms (panel A), associated PCA derived ERP components of interest (panel B), and Go RT measures (panel C) for the young and older adult groups. Note that these data are presented for the mean low (L01-L03), mid (L04-L07), and high (L08-L10) prestimulus EEG band levels (cf. the 10 individual levels) for clearer visualisation, and the ERP component topographies (panel B) are limited to those showing significant prestimulus EEG band level effects. The corresponding statistics are reported in Table 4. Interested readers are referred to the Supplementary Material (section S7) for the corresponding outcomes in the additional ERP components outside the current investigation (i.e., PN, SW, and the LP).

Table 4. Linear (direct, inverse) effects of prestimulus EEG band Level (L01-L10) on Go/NoGo processing outcomes.

\begin{tabular}{|c|c|c|c|c|c|c|c|}
\hline \multirow[b]{2}{*}{ Outcome } & \multirow[b]{2}{*}{ Effect } & \multicolumn{3}{|c|}{ Prestimulus delta sort } & \multicolumn{3}{|c|}{ Prestimulus theta sort } \\
\hline & & $F$ & $p$ & $\eta_{p}^{2}$ & $F$ & $p$ & $\eta_{p}^{2}$ \\
\hline \multirow[t]{2}{*}{ P1 } & Direct $\times \mathrm{L}<\mathrm{R}$ & 4.91 & .033 & .11 & 7.83 & .008 & .17 \\
\hline & Direct $\times \mathrm{C}>\mathrm{F} / \mathrm{P} \times \mathrm{L}<\mathrm{R}$ & & & & 10.80 & .002 & .22 \\
\hline \multirow[t]{4}{*}{ N1-1 } & Inverse & 17.53 & $<.001$ & .32 & & & \\
\hline & Inverse $\times \mathrm{C}>\mathrm{F} / \mathrm{P}$ & 5.65 & .023 & .13 & & & \\
\hline & Inverse $\times \mathrm{F}>\mathrm{P} \times \mathrm{M}>\mathrm{L} / \mathrm{R}$ & & & & 8.23 & .007 & .18 \\
\hline & Inverse $\times \mathrm{C}>\mathrm{F} / \mathrm{P} \times \mathrm{L}>\mathrm{R}$ & & & & 5.93 & .020 & .14 \\
\hline \multirow[t]{3}{*}{$\mathrm{P} 2 / \mathrm{N} 2 \mathrm{~b}$} & Direct $\times \mathrm{F}>\mathrm{P} \times \mathrm{M}>\mathrm{L} / \mathrm{R}$ & 9.54 & .004 & .20 & & & \\
\hline & Direct $\times \mathrm{Y}>\mathrm{O} \times \mathrm{L}>\mathrm{R}$ & & & & 9.57 & .004 & .20 \\
\hline & Direct $\times \mathrm{Y}>\mathrm{O} \times \mathrm{F}>\mathrm{P} \times \mathrm{M}>\mathrm{L} / \mathrm{R}$ & 15.66 & $<.001$ & .29 & & & \\
\hline \multirow[t]{4}{*}{ P3 } & Direct & 8.59 & .006 & .18 & 4.67 & .037 & .11 \\
\hline & Direct $\times \mathrm{F}>\mathrm{P}$ & 6.85 & .013 & .15 & 4.15 & .049 & .10 \\
\hline & Direct $\times \mathrm{L}>\mathrm{R}$ & 5.39 & .026 & .12 & 5.65 & .023 & .13 \\
\hline & Direct $\times \mathrm{F}>\mathrm{P} \times \mathrm{M}>\mathrm{L} / \mathrm{R}$ & & & & 11.21 & .002 & .23 \\
\hline RT (IIV) & Inverse & & & & 5.74 & .022 & .13 \\
\hline
\end{tabular}

Notes: $\mathrm{F}=$ frontal; $\mathrm{P}=$ parietal $; \mathrm{C}=$ central; $\mathrm{F} / \mathrm{P}=$ fronto-parietal mean; $\mathrm{L}=$ left hemisphere; $\mathrm{R}=$ right hemisphere; $\mathrm{M}=$ midline; $\mathrm{L} / \mathrm{R}=$ hemispheric mean; $\mathrm{Y}=$ young; $\mathrm{O}=$ older; $\mathrm{RT}$ (IIV) = intra-individual RT variability. 


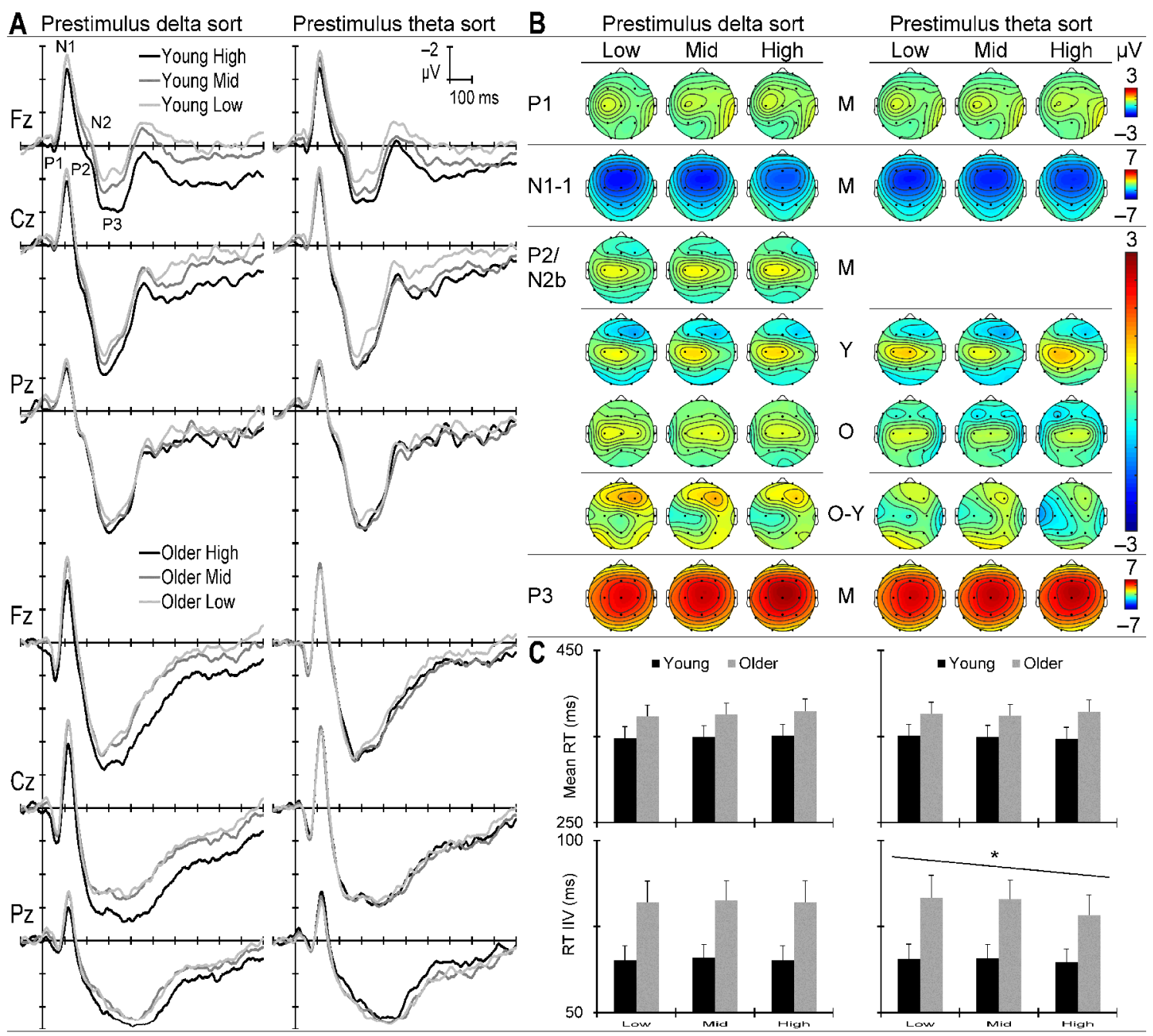

Figure 3. Effects of prestimulus EEG band level in the outcome measures. Mean data are presented for Low (mean L01-L03), Mid (mean L04-L07), and High (mean L08-L10) prestimulus EEG band levels in the prestimulus delta sort (left) and prestimulus theta sort (right). Panel A: Midline ERPs, averaged across Go/NoGo, for the young (top) and older (bottom) adult groups. ERPs are plotted with a consistent scale for easy comparison, and the key is presented in the young Fz theta sort plot (top right). The visible ERP component peaks are labelled in the young Fz delta sort plot (top left). Panel B: Topographic headmaps illustrating Level effects in the PCA derived ERP components assessed here. This figure is presented in colour online. Panel C: Mean Go RT (top) and intra-individual RT variability (IIV; bottom) for the young and older adult groups. As indicated by the asterisk, a significant linear trend was found in the prestimulus theta sorted IIV data (across groups); the sloping line above these data indicates the inverse nature of this effect. 


\subsubsection{Prestimulus Delta Level}

With increasing prestimulus delta level, right hemispheric P1 positivity increased (a direct linear trend), global and central-right N1-1 negativity decreased (inverse linear trends), and the frontal midline P2/N2b negativity became more positive (a direct linear trend). These effects did not differ with Go/NoGo, and only the frontal midline $\mathrm{P} 2 / \mathrm{N} 2 \mathrm{~b}$ effect differed with Group, being pronounced in the young adults while the older adults showed little change. Direct linear trends were also seen in P3, where increased prestimulus delta level was associated with increased global (across site), frontal, and left hemispheric $\mathrm{P} 3$ positivity across Go/NoGo and Group. Go RT measures were unaffected by prestimulus delta level (all $p \geq .079$ ).

\subsubsection{Prestimulus Theta Level}

With increasing prestimulus theta level, Pl positivity increased in the right hemisphere, particularly centrally (direct linear trends), and N1-1 negativity showed frontal-midline and central-left relative reductions (inverse linear trends) across Go/NoGo and Group. Although prestimulus theta level failed to significantly modulate $\mathrm{P} 2 / \mathrm{N} 2 \mathrm{~b}$ amplitude across $\mathrm{Go} / \mathrm{NoGo}$ and Group (all $p \geq .055$ ), higher prestimulus theta level was associated with a relative left hemispheric increase in $\mathrm{P} 2 / \mathrm{N} 2 \mathrm{~b}$ positivity in the young (cf. negativity in the older adults). Increased prestimulus theta level was associated with global, frontal (particularly midline), and lefthemispheric increases in P3 positivity across Go/NoGo and Group (direct linear trends), and behaviourally with reduced IIV across Group (an inverse linear trend).

\section{Discussion}

\subsection{Prestimulus Low-Frequency EEG Brain States and Ageing}

Prestimulus delta and theta band amplitudes were confirmed to be midline dominant, with global amplitude reductions in the older relative to young adults, consistent with the broader healthy ageing literature. Age-related topographic change was minimal, generally supporting the stability of the midline distribution in these low frequency bands, both across the lifespan, and in differing contexts (i.e., non-task vs. prestimulus). Neither band showed an age-related temporal shift (cf. Breslau et al., 1989; Klass and Brenner, 1995), although the older adult amplitudes were more anterior in delta, and more diffuse in theta.

Age-related neuronal change is well documented, including reductions in grey matter volume and white matter integrity, particularly in the frontal lobes, alterations in neurotransmitter function, including dopaminergic neurotransmission, and reductions in functional connectivity between task-relevant processing regions (Grady, 2012). Delta oscillations are thought to originate primarily in the frontal cortical regions, with anterior-posterior propagation via the 'cingulate highway', and have shown some relation to dopaminergic activity (Knyazev, 2012). Somewhat similarly, frontal midline theta oscillations have been associated with sources in the medial prefrontal (Clayton et al., 2015; Cohen, 2014; Papenberg et al., 2013) and anterior cingulate (Clayton et al., 2015) cortices, and Cohen (2014) speculated that the prefrontal cortex may support rhythmogenesis in this band. Although prestimulus theta was not localised to the frontal midline in the present study, multiple distributed theta generators have been predicted (Başar et al., 2001) and reported (Raghavachari et al., 2006) in widespread cortical regions, with these likely supporting differing functions (Cohen, 2014; Jacobs et al., 2006). It is therefore plausible that the current pattern of age-related change in prestimulus delta and theta amplitudes, both their global amplitude reduction and minimal topographical change, simply reflects one or more of these age-related neuronal changes. 
Compensatory models of cognitive ageing posit that the healthy ageing brain recruits additional (typically frontal) neural resources to counter the effects of cognitive decline/slowing in light of age-related neuronal change, which may include neural dedifferentiation (e.g., Davis et al., 2008; Goh and Park, 2009; Reuterwq-Lorenz and Park, 2010). This interpretation seems especially suited to account for the age-related prestimulus delta anteriorisation seen here, particularly given that this topography was more defined than during pre-task resting conditions in the current older, but not young adult sample (see Barry and De Blasio, 2017). However, this apparent age-related task-specific delta modulation may also reflect the adoption of differing strategies between the young and older adults.

According to the dual mechanisms of control framework (Braver, 2012), proactive and reactive control are the distinct processing modes through which cognitive control operates. Each of these control mechanisms is modelled as having prefrontal and anterior cingulate cortex involvement (Braver, 2012; De Pisapia and Braver, 2006), consistent with the reported delta and theta band source regions, although their dopaminergic system contributions are posited to differ (Braver, 2012). Braver (2012) defines proactive control as a mechanism that "relies upon the anticipation and prevention of interference before it occurs" (p.106), while reactive control is posited as a computationally efficient 'late-correction' mechanism that transiently recruits processing resources as needed, such as when an interference event (i.e., internal or external source of distraction) is detected. Consequently, proactive control processes might be best indexed by prestimulus activity, and reactive processes by poststimulus (i.e., event-related EEG and/or ERP) activity. Delta oscillations have been associated with a range of cognitive processes including attention, motivation, and salience detection (Harmony, 2013; Knyazev, 2012), although frontal delta is hypothesised to modulate distributed (and potentially distal) neural networks, enhancing internal mentation by inhibiting interfering sensory processing (Harmony, 2013). Prestimulus delta would thus seem a candidate EEG marker of proactive control, and if so, the current pattern of results suggests that the present sample of older (cf. young) adults may have preferentially emphasised this approach.

Theta oscillations have also been associated with several cognitive control processes, including attention (e.g., Başar et al., 2001; Clayton et al., 2015), motivation (e.g., Harmony, 2013), inhibition (e.g., Huster et al., 2013), performance monitoring (e.g., Papenberg et al., 2013), memory (e.g., Jacobs et al., 2006; Klimesch et al., 2007; Raghavachari et al., 2006) and conflict processing (e.g., Cohen, 2014), and may facilitate communication across brain networks (Başar et al., 2001; Clayton et al., 2015; Cohen, 2014; Papenberg et al., 2013). Given the association with cognitive control, particularly conflict processing, poststimulus (cf. prestimulus) theta activity may be a potential candidate EEG marker for reactive control processes; this hypothesis is beyond the scope of the current investigation, but should be considered in future work. If this is the case, however, it is possible that the young adults preferentially emphasised a reactive (cf. proactive) control strategy in this task.

\subsection{Age-related Change in ERP Components and Behavioural Responding}

The PCA-derived P1, N1-1, P2/N2b, and P3 components were similarly identified in the young and older adult data as anticipated, as were the PN, SW and LP presented in the Supplementary Material. P1 was centro-parietally enhanced in the older adults, broadly consistent with Barry et al. (2016a), although Go/NoGo topography did not differ between the groups. Somewhat unexpectedly, the central N1-1 was greater in the 
older (cf. young) adults ${ }^{3}$, particularly for Go. This pattern of outcomes suggests that the older group invested more effort in the early sensory (P1 and N1-1) and categorisation (N1-1) processes, further supported by their relatively reduced $\mathrm{P} 2 / \mathrm{N} 2 \mathrm{~b}$ complex which is thought to mark the choice-point in Go/NoGo categorisation in this task (Barry and De Blasio, 2013, 2015; Barry et al., 2016a, 2018; Fogarty et al., in press). Such early effort is consistent with the older adults having adopted the proactive control strategy posited to prime the attention and perception systems towards goal-directed processing (Braver, 2012). Furthermore, proactive control is capable of enhancing performance (Braver, 2012), and indeed this was seen; error rates differed minimally between the groups (see Barry et al., 2016a), and mean RT was non-significantly delayed in the older relative to young adults, although their RT variability was significantly increased as predicted. In line with the broader ageing literature, the older adult P3 showed significant anteriorisation, suggestive of a processing reduction in parietal regions (van Dinteren et al., 2014a, 2014b, 2017), and a shift to right hippocampal and dorsolateral prefrontal involvement (O'Connell et al., 2012). This age-related P3 anteriorisation was particularly pronounced in Go, implying that this shift was more relevant to Go response preparation and execution than NoGo control and termination processing (Fogarty et al., in press). This is consistent with compensatory models of cognitive ageing (e.g., Davis et al., 2008; Goh and Park, 2009; Reuter-Lorenz and Cappell, 2008; Reuter-Lorenz and Park, 2010; van Dinteren et al., 2014a, 2014b, 2017), and may have (also) contributed to the comparable performance outcomes between the groups.

\subsection{Effects of Prestimulus EEG Across the Lifespan}

The appropriate partitioning of trials into 10 prestimulus EEG band amplitude levels was confirmed in each sorting band (delta, theta) via linear trend analysis, and the associated equations indicated only minimal covariance between the prestimulus amplitudes in the sorting and non-sorting bands for each participant group (young, older adults) and condition (Go, NoGo). These findings validate the prestimulus EEG band sorting procedure utilised here, and support the independent interpretation of each band's effects on the subsequent ERP and behavioural outcomes.

\subsubsection{Delta}

Prestimulus delta band activity was confirmed to directly modulate ERP component positivity, independently of group (young, older adults) and condition (Go, NoGo), for each assessed component. That is, increased prestimulus delta amplitudes were associated with amplitude increases in the positive components, and with amplitude reductions in the negative components. While most of these effects were topographically localised, they were also seen globally (across the assessed sites) in N1-1 and P3. Prestimulus delta was not related to either of the Go response measures (mean, IIV). Together this outcome pattern generally confirms De Blasio and Barry's (2013) young adult findings in a new sample, and indicates that the prestimulus delta brain state exerts a broad influence across the processing stages conceptualised in this paradigm (see Barry and De Blasio, 2013, 2015; Barry et al., 2016a, 2018; Fogarty et al., in press), but does so in a way that is independent of behavioural outcomes in this simple task.

\footnotetext{
${ }^{3}$ This topographic interaction occurred in the absence of a main effect of group (young, older adult) and is therefore considered to reflect age-related change between the groups as opposed to an effect of the $10 \mathrm{~dB}$ difference in stimulus intensity between the groups.
} 
Consistent with earlier work (De Blasio and Barry, 2013), lower prestimulus delta levels appear to be associated with enhanced sensory processing and stimulus categorisation, as indexed here by topographicallymeaningful modulations in N1-1, and with reduced (perhaps more efficient) stimulus-specific processing, as indexed by P3 (across Go and NoGo). Importantly, these effects were common across the young and older adult groups, emphasising the robust nature of these relationships between studies and across the lifespan. Poststimulus increases in delta oscillations during mental tasks have been hypothesised to serve an inhibitory function, facilitating improved performance by reducing interfering processing (Harmony, 2013), and delta activity is known to show an inverse relationship between pre- and post-stimulus periods (Güntekin and Başar, 2016; Karakaș and Barry, 2017; Yener et al., 2016). The present findings are compatible with these premises in that low (cf. high) prestimulus delta provides the opportunity for greater poststimulus delta increases, indicating a prestimulus state of reduced cognitive engagement in which concentration is internalised (Harmony, 2013).

Age-related differences in the EEG-ERP relationships were found in the $\mathrm{P} 2 / \mathrm{N} 2 \mathrm{~b}$; prestimulus delta level inversely modulated the frontal midline negativity (N2b aspect) in the young, while the older adult $\mathrm{P} 2 / \mathrm{N} 2 \mathrm{~b}$ showed little change. This suggests that the core aspect of Go/NoGo categorisation and start of the differential Go/NoGo processing (Barry and De Blasio, 2013, 2015; Barry et al., 2016a, 2018), namely the NoGo inhibitory processing (Fogarty et al., in press), is differentially affected by the prestimulus delta state across the lifespan. However, this result could also reflect a difference between the groups in their adoption of proactive vs. reactive control mechanisms (Braver, 2012) as discussed earlier; this possibility cannot be dismissed or confirmed here, and remains to be resolved in future work.

Overall, the prestimulus delta findings of age-related EEG-ERP change in P2/N2b and consistency in P3 are largely compatible with earlier resting-state brain dynamics work conducted by Polich (1997a). However, the age-related consistency in the relationship between prestimulus delta and N1-1 (a major subcomponent of the N1; Näätänen and Picton, 1987) is somewhat incompatible with Polich's (1997a) N1 findings; this is likely attributable to one or more of the methodological (i.e., PCA vs. peak-picked ERP quantification; resting vs. immediately-prestimulus EEG) and/or paradigmatic (i.e., equiprobable vs. Oddball paradigm) differences between these studies.

\subsubsection{Theta}

Consistent with prior behavioural findings in young adults (De Blasio and Barry, 2013), Go prestimulus theta was unrelated to mean RT within or between the young and older adult groups, although a novel inverse relationship was uncovered (across the groups) in IIV. Prestimulus theta directly modulated regional positivity in each investigated ERP component, although P3 also showed this effect globally across the assessed sites. These findings were independent of stimulus condition (Go, NoGo), and only the P2/N2b effect differed between the young and older adults. Increased prestimulus theta amplitudes were therefore (predominantly) associated with focal increases in the positive P1 and P3 components, with focal decreases in the negative N1-1 component, and with improved response consistency across the young and older adults, together demonstrating prestimulus theta's impact across a number of task-related processing stages and subsequent response performance. This pattern of findings differs notably from prior work in this paradigm in young adults (De Blasio and Barry, 2013); the present results show a novel effect in P1, shifts in the topographic focus of effects in N1-1 and P2/N2b, and the absence of stimulus-specific interactions in N1-1, P2/N2b and P3. Moreover, the novel IIV effect associates higher (cf. lower) prestimulus theta levels with improved processing 
outcomes, again contrary to prior interpretation (De Blasio and Barry, 2013).

Across the young and older adult groups, higher prestimulus theta levels were associated with early sensory processing enhancement, indicated by focal P1 elevations, and with diminished ongoing sensory and early stimulus categorisation processing, indexed by focal N1-1 reductions (Barry and De Blasio, 2013, 2015; Barry et al., 2016a, 2018; Fogarty et al., in press). However, these modulations occurred in focal regions (i.e., P1: central right; N1-1: frontal midline and central left), and thus their impact on these processing stages may not be extensive. Subsequent stimulus-specific processing was generally enhanced as indicated by elevations in Go and NoGo P3 alike, posited (in this task) as reflecting response preparation and execution (Barry and De Blasio, 2013, 2015; Barry et al., 2016a, 2018), and control and response termination (Fogarty et al., in press), respectively. Focal increases in theta activity have been associated with memory (Jacobs et al., 2006; Klimesch et al., 2007; Raghavachari et al., 2006), conflict (Cohen, 2014), and attentional and cognitive control processes (Clayton et al., 2015). While conflict processing seems less likely given its distinct and well known association with fronto-midline theta, it is plausible that the higher prestimulus theta brain states, assessed here more broadly across the midline sites, might have reflected prestimulus working memory engagement (Raghavachari et al., 2006), decreased memory load (Jacobs et al., 2006), and/or the reorientation of auditory attention (Clayton et al., 2015), processes that could each have contributed to the above pattern of improved outcomes. Higher prestimulus theta levels were also associated with greater consistency (across the young and older adult groups) in Go response performance, indicated by the decreased IIV. Papenberg et al. (2013) reported a similar relationship between event-related spectral theta power and RT variability in a Cued Go/NoGo task across a lifespan sample that included children, adolescents, young and older adults. Interestingly, it was reported that theta power ceased to be an important predictor of RT variability when (poststimulus) theta inter-trial phase coherence was included in the regression analysis, leading Papenberg and colleagues to speculate that the variability (cf. magnitude) of the underlying processing is more important in determining performance variability. Phase (cf. amplitude) dynamics provide additional and complementary insight into the alignment (at a given point; e.g., Barry et al., 2014) and/or synchrony (temporal and/or spatial; e.g., Papenberg et al., 2013) of the ongoing oscillations. Each of these phase measures thus plays an important role in elucidating the fundamental EEG-ERP dynamics, however, the volume and complexity of their data (e.g., see Barry et al., 2014) place them beyond the scope of the (already sizable) present investigation. Future and independent examination of these measures is therefore advantageous, as is the combined assessment of amplitude and phase dynamics for a more detailed examination of a single (cf. multiple) EEG band of interest.

In addition to the prestimulus theta effects common across the young and older adults, a group interaction was seen in the $\mathrm{P} 2 / \mathrm{N} 2 \mathrm{~b}$ complex. Although this interaction was independent of Go/NoGo, the left hemispheric bias was directly modulated for this component's P2 (positive, Go) aspect in the young, and for its $\mathrm{N} 2 \mathrm{~b}$ (negative, NoGo) aspect in the older adults. The P2/N2b complex is thought to mark the resolution of Go/NoGo categorisation in this task (Barry and De Blasio, 2013, 2015; Barry et al., 2016a, 2018; Fogarty et al., in press), suggesting that the prestimulus theta brain state differentially enhanced Go/NoGo categorisation across the lifespan. Again however, the young and older adults may have differed in their strategy in this task (i.e., proactive vs. reactive control; Braver, 2012), which might (at least partially) have contributed to this outcome. 
The present prestimulus theta findings of age-related EEG-ERP relationship consistency in P3, and change in P2/N2b, are compatible with earlier resting-state work by Polich (1997a), while the age-related consistency of the present N1-1 effects are incongruous with his findings in N1. In comparison with earlier brain dynamics research (e.g., De Blasio and Barry, 2013; Polich, 1997a), the improved methodology utilised in the present study, including the PCA separation of underlying ERP subcomponents, should be more sensitive in detecting fundamental EEG-ERP dynamics, and this likely contributes to discrepancies between the present and prior investigations.

\subsection{Summary and Conclusion}

Low-frequency EEG delta and theta band activity have been implicated in healthy and pathological ageing, thus the consistency in their prestimulus influence on processing outcomes may provide insight into agerelated cognitive decline, particularly given the documented age-related change in EEG, ERPs, and behavioural performance.

Assessing these measure independently, prestimulus delta and theta band topography, Go and NoGo ERP component amplitudes, and Go response performance each met expectations (including those reflecting healthy age-related change) in the present samples of healthy young and older adults in this simple equiprobable auditory Go/NoGo paradigm. That is, prestimulus delta and theta band amplitudes were predominantly midline and reduced in the older relative to young adults, ERP component amplitudes were topographically shifted, particularly the P3 (which showed the typical older adult anteriorisation), and the older (cf. young) adults showed significantly increased RT variability. Such change is consistent with compensatory accounts of cognitive ageing, particularly in light of age-related neuronal change, but may also reflect the possible adoption of differing task strategies between the groups; the latter interpretation requires further investigation.

When assessing their contributions, prestimulus delta and theta band amplitudes each directly modulate ERP positivity across the assessed components, and prestimulus theta inversely modulated RT variability. Importantly, the nature of the ERP component modulations differed between the assessed bands, despite their prestimulus EEG-ERP relationships appearing broadly similar. Prestimulus delta primarily modulated the early sensory and stimulus categorisation processes, while theta was more associated with the later stimulus-specific processes, and this likely contributed to the modulation of RT variability seen in this band. These outcomes were generally consistent across the groups despite the (sometimes substantial) age-related change in each individual measure, with only one of the four components of interest (the P2/N2b complex) showing age-related change in these prestimulus EEG-ERP relationships. Mazaheri and Picton's (2005) shared-generator hypothesis provides an elegant underpinning for the majority of these findings, proposing that EEG rhythms and ERP components share neuronal generators. Accordingly, any age-related change in these generators, whether physiological or pathological, structural and/or functional, and/or their ability to recruit compensatory or additional neuronal resources, would impact each measure and likely result in (or contribute to) the maintenance of their dynamic relationship, as primarily found here. If so, the replication of the current pattern of prestimulus EEG-ERP dynamics in new healthy ageing samples, as well as non-normative (e.g., mild cognitive impairment, pathological ageing, or other clinical or sub-clinical) populations, would provide further evidence for this hypothesis. 
Age-related change in the prestimulus EEG-ERP dynamics were found between each assessed band (delta, theta) and the $\mathrm{P} 2 / \mathrm{N} 2 \mathrm{~b}$ complex, suggesting that the core aspect of Go/NoGo categorisation (Barry and De Blasio, 2013, 2015; Barry et al., 2016a, 2018; Fogarty et al., in press) is affected differentially by prestimulus low-frequency EEG across the life-span. Again, the exact nature of these effects differed between the bands; delta modulated the NoGo N2b aspect of the P2/N2b complex in the young (cf. older) adults, while theta modulated the Go P2 aspect in the young, and the NoGo N2b aspect in the older adults. These age-related differential effects in EEG-ERP amplitude dynamics were found in the absence of significant (between-group) variation in task-related response speed and variability, and may therefore indicate an adaptive shift in such dynamics to maintain performance, as would be predicted by compensatory theories of healthy ageing (e.g., Davis et al., 2008; Goh and Park, 2009; Reuter-Lorenz and Cappell, 2008; Reuter-Lorenz and Park, 2010). Anecdotally, despite the consistent delivery of task instructions equally emphasising response speed and accuracy, following the testing session the young adults tended to enquire about the former, while the older adults generally enquired about the latter. It is therefore possible that these groups adopted different strategies in this task. The age-related prestimulus EEG-P2/N2b discrepancies instead may reflect (at least partially) the differential implementation of proactive vs. reactive control mechanisms (Braver, 2012), for example. This was an unforeseen potential limitation of the present study, and future work should thus seek to elucidate the prestimulus EEG and ERP markers of Braver's (2012) dual mechanisms of control, and/or assess the impact of strategy on each measure. A competing account for this outcome can be derived from the complex nature of this PCA-derived component. The $\mathrm{P} 2 / \mathrm{N} 2 \mathrm{~b}$ is an amalgam of temporally adjacent and at least partially overlapping stimulus-specific components each carrying comparatively little data variance. Subsequently, the Go P2 and NoGo N2b tend to be forced together when using a combined PCA, having both Go and NoGo data as input; for methodological background see Barry et al. (2016b). Age-related change may differ in the neural generators of these topographically distinct components, and despite the absence of prestimulus EEG band Level $\times$ Group $\times$ Stimulus interaction effects in this component, their unification could possibly obscure their independent relationships with the prestimulus EEG low-frequency brain states, particularly when considered in relation to the shared-generator hypothesis (Mazaheri and Picton, 2005). In accordance with recent methodological recommendations (Barry et al., 2016b, 2018), future prestimulus EEG-ERP amplitude dynamics investigations should thus utilise separate Go and NoGo PCAs to more precisely quantify the ERP indices of the stimulus-specific processing stages in this paradigm.

In conclusion, this investigation makes a significant contribution to our understanding of the influence of the low-frequency prestimulus EEG brain states on processing outcomes in this simple equiprobable auditory Go/NoGo paradigm, and their consistency across the life-span in healthy ageing. The present findings, in both the prestimulus EEG-ERP and prestimulus EEG-RT dynamics, generally confirmed and extended prior young adult research in delta (De Blasio and Barry, 2013), although they differ somewhat from prior work in theta and instead provide new (and theoretically improved) insights into dynamics in that band. More importantly, this appears to be only the second study to investigate the consistency in EEG-ERP amplitude dynamics in an ageing context (also see Polich, 1997a). The robust nature of the EEG-ERP relationships between prestimulus low-frequency EEG and P3 across the lifespan were supported, and evidence indicated that the age-related maintenance of such dynamics extends beyond these EEG-ERP couplings. Many of the additional findings (in both the components of interest and the PCA derived subcomponents assessed in the Supplementary Material, as 
well as in RT), are novel. These may (at least partially) be attributable to the innovative methodological improvements utilised here, including the assessment of prestimulus EEG band amplitude across the core band topography (cf. a single site), and PCA (cf. peak-picked) quantification of the ERP component amplitudes. However, the modest (yet reasonable) sample sizes ${ }^{4}$, possibility of differing task strategy adoption between the groups, and the use of combined (cf. separate) Go and NoGo PCAs in ERP quantification may have contributed to these outcomes; these limitations should be considered in future work. Although replication of these findings is first required, their investigation in pathological ageing samples would appear promising in the search to elucidate adaptive and maladaptive age-related change/s in brain dynamics, and thus identify biomarkers of cognitive decline.

\footnotetext{
${ }^{4}$ Although care was taken in the selection of appropriate analysis and multiple testing correction techniques, the young $(N=20)$ and older $(N=20)$ adult sample sizes were less than ideal, and may still have contributed somewhat to the present findings given the number of analyses conducted. In an attempt to minimise this likelihood, one univariate MANOVA was conducted per ERP component per assessed band, each with a priori planned single degree of freedom contrasts, and the FDR correction was applied for the testing of multiple bands. Moreover, although the primary (within-subjects) factor of interest (prestimulus EEG band level) had 10 levels, yielding output for 9 contrasts (which may have increased the possibility of Type-1 errors), only the planned linear contrast, and its topographical and group interactions, were examined and interpreted here. Nevertheless, future investigations should seek to include larger samples to further minimise this potential limitation.
} 


\section{Acknowledgements}

This research has been conducted with the support of the Australian Government Research Training Program Scholarship.

We thank the Illawarra Retirement Trust (IRT) and the management of IRT Links Seaside for their kind assistance in providing facilities and encouraging resident participation in this project. 


\section{References}

Alperin, B.R., Mott, K.K., Rentz, D.M., Holcomb, P.J., Daffner, K.R., 2014. Investigating the age-related "anterior shift" in the scalp distribution of the P3b component using principal component analysis. Psychophysiol. 51, 620-633. doi: 10.1111/psyp. 12206

Babiloni, C., Binetti, G., Cassarino, A., Dal Forno, G., Del Percio, C., Ferreri, F., Ferri, R., Frisoni, G., Galderisi, S., Hirata, K., Lanuzza, B., Miniussi, C., Mucci, A., Nobili, F., Rodriguez, G., Romani, G.L., Rossini, P.M., 2006. Sources of cortical rhythms in adults during physiological aging: A multicentric EEG study. Hum. Brain Mapp. 27, 162-172. doi: 10.1002/hbm.20175

Barry, R.J., 2009. Evoked activity and EEG phase resetting in the genesis of auditory Go/NoGo ERPs. Biol. Psychol. 80, 292-299. doi: 10.1016/j.biopsycho.2008.10.009

Barry, R.J., De Blasio, F.M., 2013. Sequential processing in the equiprobable auditory Go/NoGo task: A temporal PCA study. Int. J. Psychophysiol. 89, 123-127. doi: 10.1016/j.ijpsycho.2013.06.012

Barry, R.J., De Blasio, F.M., 2015. Performance and ERP components in the equiprobable go/no-go task: Inhibition in children. Psychophysiology 52, 1228-1237. doi: 10.1111/psyp. 12447

Barry, R.J., De Blasio, F.M., 2017. EEG differences between eyes-closed and eyes-open resting remain in healthy ageing. Biol. Psychol. 129, 293-304. doi: 10.1016/j.biopsycho.2017.09.010

Barry, R.J., De Blasio, F.M., Cave, A.E., 2016a. Sequential processing in young and older adults in the equiprobable auditory Go/NoGo task. Clin. Neurophysiol. 127, 2273-2285. doi: 10.1016/j.clinph.2016.02.010

Barry, R.J., De Blasio, F.M., De Pascalis, V., Karamacoska, D., 2014. Preferred EEG brain states at stimulus onset in a fixed interstimulus interval equiprobable auditory Go/NoGo task: A definitive study. Int. J. Psychophysiol. 94, 42-58. doi: 10.1016/j.ijpsycho.2014.07.005

Barry, R.J., De Blasio, F.M., Fogarty, J.S., 2018. A processing schema for children in the auditory equiprobable Go/NoGo task: ERP components and behaviour. Int. J. Psychophysiol. 123, 74-79. doi: 10.1016/j.ijpsycho.2017.10.014

Barry, R.J., De Blasio, F.M., Fogarty, J.S., Karamacoska, D., 2016b. ERP Go/NoGo condition effects are better detected with separate PCAs. Int. J. Psychophysiol. 106, 50-64. doi: 10.1016/j.ijpsycho.2016.06.003

Başar, E., Schürman, M., Sakowitz, O., 2001. The selectively distributed theta system: Functions. Int. J. Psychophysiol. 39, 197-212. doi: 10.1016/S0167-8760(00)00141-0

Benjamini, Y., Hochberg, Y., 1995. Controlling the false discovery rate: A practical and powerful approach to multiple testing. J. Roy. Stat. Soc. B Met. 57, 289-300.

Braver, T.S., 2012. The variable nature of cognitive control: A dual mechanisms framework. Trends Cogn. Sci. 16, 106-113. doi: 10.1016/j.tics.2011.12.010

Breslau, J., Starr, A., Sicotte, N., Higa, J., Buchsbaum, M.S., 1989. Topographic EEG changes with normal aging and SDAT. Electroen. Clin. Neuro. 72, 281-289. doi: 10.1016/00134694(89)90063-1

Čeponienè, R., Westerfield, M., Torki, M., Townsend, J., 2008. Modality-specificity of sensory aging in vision and audition: Evidence from event-related potentials. Brain Res. 1215, 53-68. doi: 10.1016/j.brainres.2008.02.010 
Clayton, M.S., Yeung, N., Cohen Kadosh, R., 2015. The roles of cortical oscillations in sustained attention. Trends Cogn. Sci. 19, 188-195. doi: 10.1016/j.tics.2015.02.004

Cohen, M.X., 2014. A neural microcircuit for cognitive conflict detection and signalling. Trends Neurosci. 37, 480-490. doi: 10.1016/j.tins.2014.06.004

Croft, R.J., Barry, R.J., 2000. EOG correction of blinks with saccade coefficients: A test and revision of the aligned-artifact average solution. Clin. Neurophysiol. 111, 444-451. doi: 10.1016/S13882457(99)00296-5

Cummins, T.D.R., Finnigan, S., 2007. Theta power is reduced in healthy cognitive aging. Int. J. Psychophysiol. 66, 10-17. doi: 10.1016/j.ijpsycho.2007.05.008

Davis, S.W., Dennis, N.A., Daselaar, S.M., Fleck, M.S., Cabeza, R., 2008. Qué PASA? The posterioranterior shift in aging. Cereb. Cortex 18:1201-1209. doi: 10.1093/cercor/bhm155

De Blasio, F.M., Barry, R.J., 2013. Prestimulus delta and theta determinants of ERP responses in the Go/NoGo task. Int. J. Psychophysiol. 87, 279-288. doi: 10.1016/j.ijpsycho.2012.09.016

Delorme, A., Makeig, S., 2004. EEGLAB: An open source toolbox for analysis of single-trial EEG dynamics including independent component analysis. J. Neurosci. Meth. 134, 9-21. doi: 10.1016/j.jneumeth.2003.10.009

De Pisapia, N., Braver, T.S., 2006. A model of dual control mechanisms through anterior congulate and prefrontal cortex interactions. Neurocomputing 69, 1322-1326. doi: 10.1016/j.neucom.2005.12.100

Dien, J., 2010. The ERP PCA Toolkit: An open source program for advanced statistical analysis of eventrelated potential data. J. Neurosci. Meth. 187,138-145. doi: 10.1016/j.jneumeth.2009.12.009

Duffy, F.H., Albert, M.S., McAnulty, G., Garvey, A.J., 1984. Age-related differences in brain electrical activity of healthy subjects. Ann. Neurol. 16, 430-438. doi: 10.1002/ana.410160403

Dykiert, D., Der, G., Starr, J.M., Deary, I.J., 2012. Age differences in intra-individual variability in simple and choice reaction time: Systematic review and meta-analysis. PLoS ONE 7, e45759. doi: 10.1371/journal.pone.0045759

Emek-Savaş, D.D., Güntekin, B., Yener, G.G., Başar, E., 2016. Decrease of delta oscillatory responses is associated with increased age in healthy elderly. Int. J. Psychophysiol. 103, 103-109. doi: 10.1016/j.ijpsycho.2015.02.006

Falkenstein, M., Yordanova, J., Kolev, V., 2006. Effects of aging on slowing of motor-response generation. Int. J. Psychophysiol. 59, 22-29. doi: 10.1111/j.1469-8986.2007.00602.x

Fell, J., Dietl, T., Grunwald, T., Kurthen, M., Klaver, P., Trautner, P., Schaller, C., Elger, C.E., Fernández, G., 2004. Neural bases of cognitive ERPs: More than phase reset. J. Cognitive Neurosci. 16, 1595-1604. doi: 10.1162/0898929042568514

Fogarty, J.S., Barry, R.J., De Blasio, F.M., Steiner, G.Z., in press. ERP components and behaviour in the auditory equiprobable Go/NoGo task: Inhibition in young adults. Psychophysiol. doi: $10.1111 /$ psyp. 13065

Ford, J.M., Hink, R.F., Hopkins III, W.F., Roth, W.T., Pfefferbaum, A., Kopell, B.S., 1979. Age effects on event-related potentials in a selective attention task. Gerontology 34, 388-395. doi: $10.1093 /$ geronj/34.3.388 
Fozard, J.L., Vercruyssen, M., Reynolds, S.L., Hancock, P.A., Quilter, R.E., 1994. Age differences and changes in reaction time: The Baltimore longitudinal study of aging. J. Gerontol. 49, 179-189. doi: 10.1093/geronj/49.4.P179

Friedman, D., Kazmerski, V., Fabiani, M., 1997. An overview of age-related changes in the scalp distribution of P3b. Electroen. Clin. Neuro. 104, 498-513. doi: 10.1016/S0168-5597(97)00036-1

Fulton, S.E., Lister, J.J., Harrison Bush, A.L., Edwards, J.D., Andel, R., 2015. Mechanisms of the hearing-cognition relationship. Semin. Hear. 36, 140-149. doi: 10.1055/s-0035-1555117

Goh, J.O., Park, D.C., 2009. Neuroplasticity and cognitive aging: The scaffolding theory of aging and cognition. Restor. Neurol. Neuros. 27, 391-403. doi: 10.3233/RNN-2009-0493

Gorsuch, R. L., 1983. Factor analysis (2nd ed.). Hillsdale, NJ: Lawrence Erlbaum Associates, Inc.

Grady, C., 2012. The cognitive neuroscience of ageing. Nat. Rev. Neurosci. 13, 491-505. doi: $10.1038 / \mathrm{nrn} 3256$

Grassi, M., Borella, E., 2013. The role of auditory abilities in basic mechanisms of cognition in older adults. Front. Aging Neurosci. 5, 59. doi: 10.3389/fnagi.2013.00059

Güntekin, B., Başar, E., 2016. Review of evoked and event-related delta responses in the human brain. Int. J. Psychophysiol. 103, 43-52. doi: 10.1016/j.ijpsycho.2015.02.001

Harmony, T., 2013. The functional significance of delta oscillations in cognitive processing. Front. Integr. Neurosci. 7, 83. doi: 10.3389/fnint.2013.00083

Howell, D.C., 1997. Statistical Methods for Psychology, 4th edn., Duxbury Press, California.

Huster, R.J., Enriquez-Geppert, S., Lavallee, C.F., Falkenstein, M., Herrmann, C.S., 2013. Electroencephalography of response inhibition tasks: Functional networks and cognitive contributions. Int. J. Psychophysiol. 87, 217-233. doi: 10.1016/j.jjpsycho.2012.08.001

Jacobs, J., Hwang, G., Curran, T., Kahana, M.J., 2006. EEG oscillations and recognition memory: Theta correlates of memory retrieval and decision making. NeuroImage 32, 978-987. doi: 10.1016/j.neuroimage.2006.02.018

Karakaș, S., Barry, R.J., 2017. A brief historical perspective on the advent of brain oscillations in the biological and psychological disciplines. Neurosci. Biobehav. R. 75, 335-347. doi: 10.1016/j.neubiorev.2016.12.009

Kayser, J., Tenke, C.E., 2003. Optimizing PCA methodology for ERP component identification and measurement: Theoretical rationale and empirical evaluation. Clin. Neurophysiol. 114, 23072325. doi: 10.1016/S1388-2457(03)00241-4

Klass, D.W., Brenner, R.P., 1995. Electroencephalography of the elderly. J. Clin. Neurophysiol. 12, 116131.

Klimesch, W., Sauseng, P., Hanslmayr, S., Gruber, W., Freunberger, R., 2007. Event-related phase reorganization may explain evoked neural dynamics. Neurosci. Biobehav. R. 31, 1003-1016. doi: 10.1016/j.neubiorev.2007.03.005

Knyazev, G.G., 2012. EEG delta oscillations as a correlate of basic homeostatic and motivational processes. Neurosci. Biobehav. R. 36, 677-695. doi: 10.1016/j.neubiorev.2011.10.002

MacDonald, S.W.S., Li, S-C., Bäckman, L., 2009. Neural underpinnings of within-person variability in cognitive functioning. Psychol. Aging 24, 792-808. doi: 10.1037/a0017798 
Mazaheri, A., Jensen, O., 2008. Asymmetric amplitude modulations of brain oscillations can generate slow evoked responses. J. Neurosci. 28, 7781-7787. doi: 10.1523/JNEUROSCI.1631-08.2008

Mazaheri, A., Picton, T.W., 2005. EEG spectral dynamics during discrimination of auditory and visual targets. Cogn. Brain Res. 24, 81-96. doi: 10.1016/j.cogbrainres.2004.12.013

Näätänen, R., Picton, T., 1987. The N1 wave of the human electric and magnetic response to sound: A review and an analysis of the component structure. Psychophysiology 24, 375-425. doi: 10.1111/j.1469-8986.1987.tb00311.x

O'Brien, R.G., Kaiser, M.K., 1985. MANOVA method for analysing repeated measures designs: An extensive primer. Psychol. Bull. 97, 316-333. doi: 10.1037/0033-2909.97.2.316

O'Connell, R.G., Balsters, J.H., Kilcullen, S.M., Campbell, W., Bokde, A.W., Lai, R., Upton, N., Robertson, I.H., 2012. A simultaneous ERP/fMRI investigation of the P300 aging effect. Neurobiol. Aging 33, 2448-2461. doi: 10.1016/j.neurobiolaging.2011.12.021

Papenberg, G., Hämmerer, D., Müller, V., Lindenberger, U., Li, S.-C., 2013. Lower theta inter-trial phase coherence during performance monitoring is related to higher reaction time variability: A lifespan study. NeuroImage 83, 912-920. doi: 10.1016/j.neuroimage.2013.07.032

Pfefferbaum, A., Ford, J.M., Roth, W.T., Kopell, B.S., 1980. Age-related changes in auditory eventrelated potentials. Electroen. Clin. Neuro. 49, 266-276. doi: 10.1016/0013-4694(80)90221-7

Picton, T.W., Bentin, S., Berg, P., Donchin, E., Hillyard, S.A., Johnson, R., Jr., Miller, G.A., Ritter, W., Ruchkin, D.S., Rugg, M.D., Taylor, M.J., 2000. Guidelines for using human event-related potentials to study cognition: Recording standards and publication criteria. Psychophysiol. 37, 127-152. doi: $10.1111 / 1469-8986.3720127$

Polich, J., 1997a. EEG and ERP assessment of normal aging. Electroen. Clin. Neuro. 104, 244-256. doi: 10.1016/S0168-5597(97)96139-6

Polich, J., 1997b. On the relationship between EEG and P300: Individual differences, aging, and ultradian rhythms. Int. J. Psychophysiol. 26, 299-317. doi: 10.1016/S0167-8760(97)00772-1

Raghavachari, S., Lisman, J.E., Tully, M., Madsen, J.R., Bromfield, E.B., Kahana, M.J., 2006. Theta oscillations in human cortex during a working-memory task: Evidence for local generators. J. Neurophysiol. 95, 1630-1638. doi: 10.1152/jn.00409.2005

Reuter-Lorenz, P.A., Cappell, K.A., 2008. Neurocognitive aging and the compensation hypothesis. Curr. Dir. Psychol. Sci. 17, 177-182. doi: 10.1111/j.1467-8721.2008.00570.x

Reuter-Lorenz, P.A., Park, D.C., 2010. Human neuroscience and the aging mind: A new look at old problems. J. Gerontol. B Psychol. Sci. Soc. Sci. 65B, 405-415. doi: 10.1093/geronb/gbq035

Sauseng, P., Klimesch, W., Gruber, W.R., Hanslmayr, S., Freunberger, R., Doppelmayr, M., 2007. Are event-related potential components generated by phase resetting of brain oscillations? Neuroscience 146, 1435-1444. doi: 10.1016/j.neuroscience.2007.03.014

Schmiedek, F., Lövdén, M., Lindenberger, U., 2009. On the relation of mean reaction time and intraindividual reaction time variability. Psychol. Aging 24, 841-857. doi: 10.1037/a0017799

Steiner, G.Z., Gonsalvez, C.J., De Blasio, F.M., Barry, R.J., 2016. Electrophysiology of memoryupdating differs with age. Front. Aging Neurosci. 8, 136. doi: 10.3389/fnagi.2016.00136

Storey, J., Rowland, J., Basic, D., Conforti, D., Dickson, H., 2004. The Rowland Universal Dementia 
Assessment Scale (RUDAS): A multicultural cognitive assessment scale. Int. Psychogeriatr. 16, 13-31. doi: 10.1017/S1041610204000043

Tabachnick, B.G., Fidell, L.S., 2013. Using Multivariate Statistics, 6th edn., Pearson Education Limited, England.

van Dijk, H., van der Werf, J., Mazaheri, A., Medendrop, W.P., Jensen, O., 2010. Modulations in oscillatory activity with amplitude asymmetry can produce cognitively relevant event-related responses. P. Natl. Acad. Sci. USA 107, 900-905. doi: 10.1073/pnas.0908821107

van Dinteren, R., Arns, M., Jongsma, M.L.A., Kessels, R.P.C., 2014a. Combined frontal and parietal P300 amplitudes indicate compensated cognitive processing across the lifespan. Front. Aging Neurosci. 6, 294. doi: 10.3389/fnagi.2014.00294

van Dinteren, R., Arns, M., Jongsma, M.L.A., Kessels, R.P.C., 2014b. P300 development across the lifespan: A systematic review and meta-analysis. PLoS ONE 9, e87347. doi:

10.1371/journal.pone.0087347

van Dinteren, R., Huster, R.J., Jongsma, M.L.A., Kessels, R.P.C., Arns, M., 2017. Differences In cortical sources of the event-related P3 potential between young and old participants indicate frontal compensation. Brain Topogr. doi: 10.1007/s10548-016-0542-y

Vasey, M.W., Thayer, J.F., 1987. The continuing problem of false positives in repeated measures ANOVA in psychophysiology: A multivariate solution. Psychophysiology 24, 479-486. doi: 10.1111/j.1469-8986.1987.tb00324.x

Vysata, O., Kukal, J., Prochazka, A., Pazdera, L., Valis, M., 2012. Age-related changes in the energy and spectral composition of EEG. Neurophysiology 44, 63-67. doi: 10.1007/s11062-012-9268-y

Yener, G.G., Emek-Savaș, D.D., Lizio, R., Çavuşoğlu, B., Carducci, F., Ada, E., Güntekin, B., Babiloni, C.C., Başar, E., 2016. Frontal delta event-related oscillations relate to frontal volume in mild cognitive impairment and healthy controls. Int. J. Psychophysiol. 103, 110-117. doi:

10.1016/j.ijpsycho.2015.02.005

Yordanova, J., Kolev, V., Hohnsbein, J., Falkenstein, M., 2004. Sensorimotor slowing with ageing is mediated by a functional dysregulation of motor-generation processes: Evidence from highresolution event-related potentials. Brain 127, 351-362. doi: 10.1093/brain/awh042 


\section{Prestimulus delta and theta contributions to equiprobable \\ Go/NoGo processing in healthy ageing}

\section{Supplementary Material}

Frances M. De Blasio and Robert J. Barry

\section{Table of Contents}

S1. Data Quantification 1

S2. Prestimulus EEG contributions from overlapping phase-locked spectra......................................

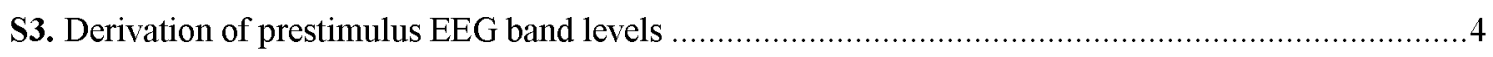

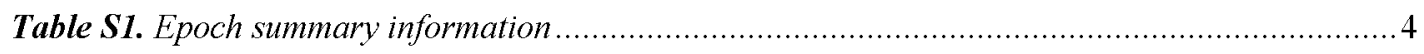

S4. PCA component identification and consistency with Barry et al. (2016a) ................................. 4

S5. Grand mean and Go/NoGo PCA component topography.......................................................

Table S2. Grand mean ERP component topography and Go/NoGo statistics................................... 8

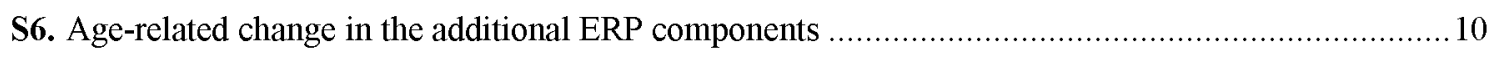

Table S3. Group effects across prestimulus EEG band Level ..................................................... 9

S7. Linear effects of prestimulus EEG band level in the additional ERP components .............................11

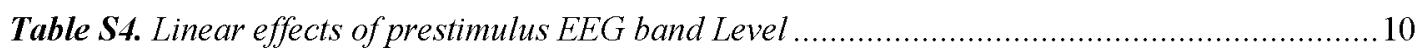

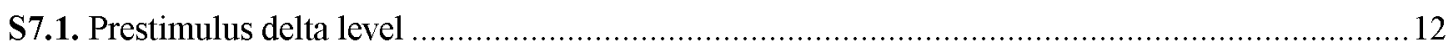

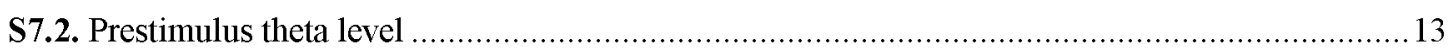

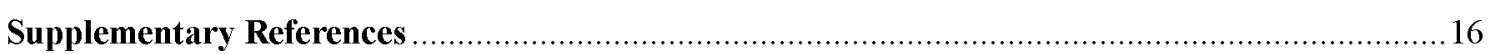




\section{S1. Data Quantification}

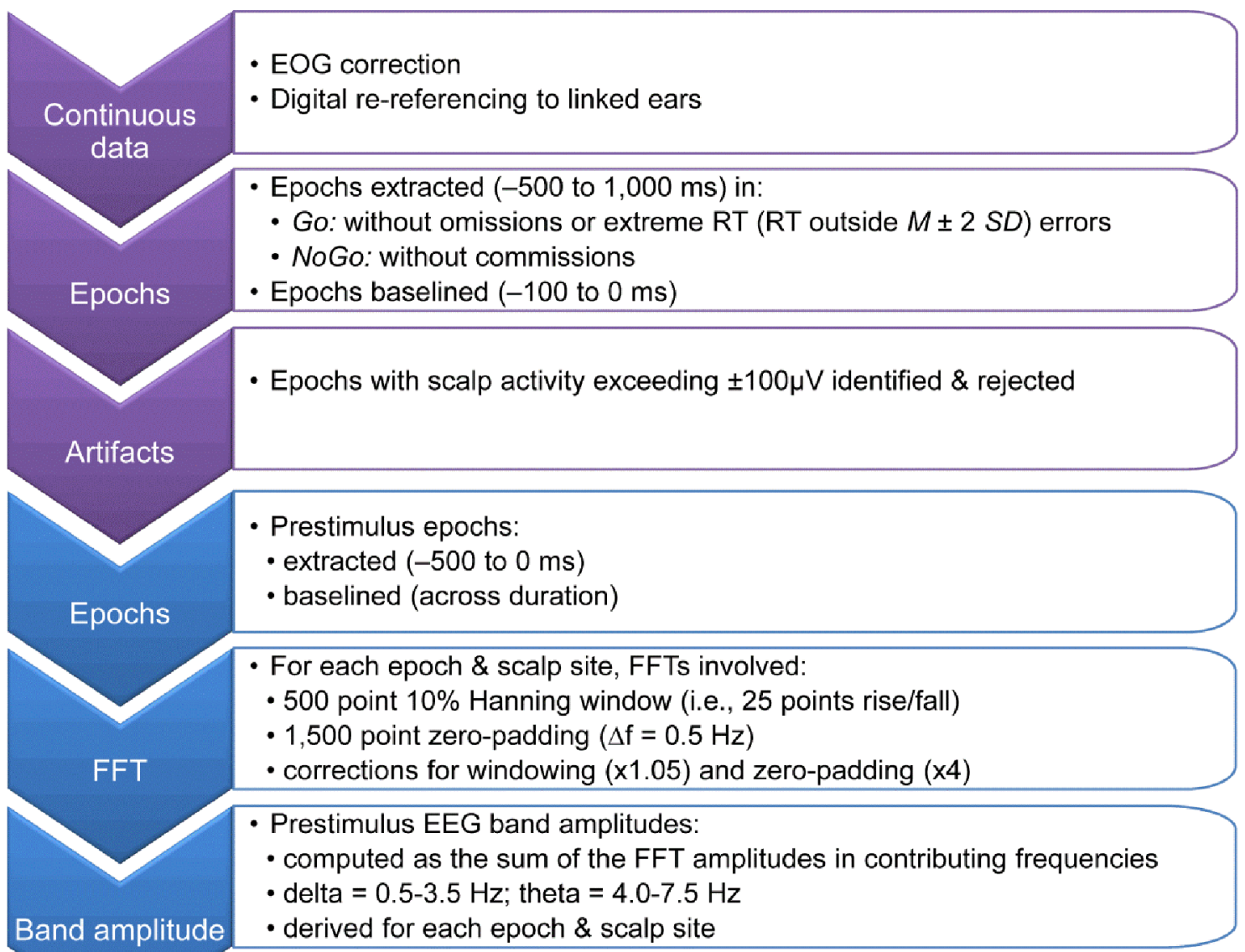

\begin{tabular}{|l|l|}
\multicolumn{1}{|l}{$\begin{array}{l}\text { Region of } \\
\text { interest }\end{array}$} & $\begin{array}{l}\text { Separately for prestimulus delta \& theta: } \\
\text { - topographic analyses of the mean amplitude \& variability (across Go/NoGo) } \\
\text { Interest }\end{array}$ \\
\hline & $\begin{array}{l}\text { - Pre/post-stimulus epochs: } \\
\text { - retrieved } \\
\text { - cut }(-100 \text { to } 1,000 \mathrm{~ms})\end{array}$ \\
\hline
\end{tabular}

\begin{tabular}{|c|c|}
\hline Prestimulus & $\begin{array}{l}\text { - Separately for prestimulus delta \& theta: } \\
\text { - ROI band amplitude used to sort the epochs (within-subjects) } \\
\text { - sorted epochs sub-divided into } 10 \text { levels of equal size (excess epochs } \\
\text { excluded) }\end{array}$ \\
\hline
\end{tabular}

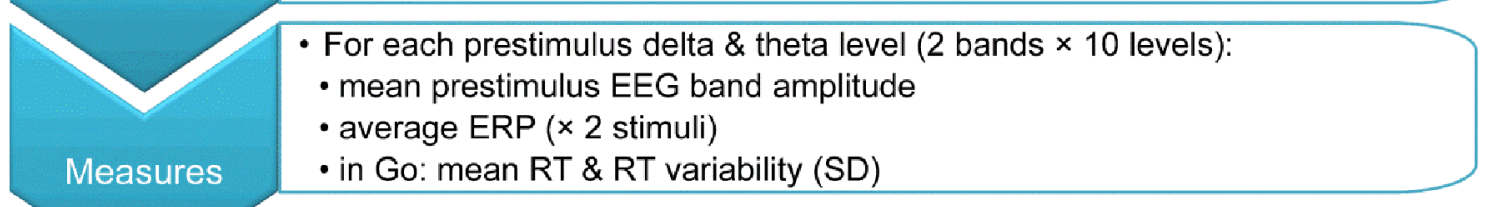

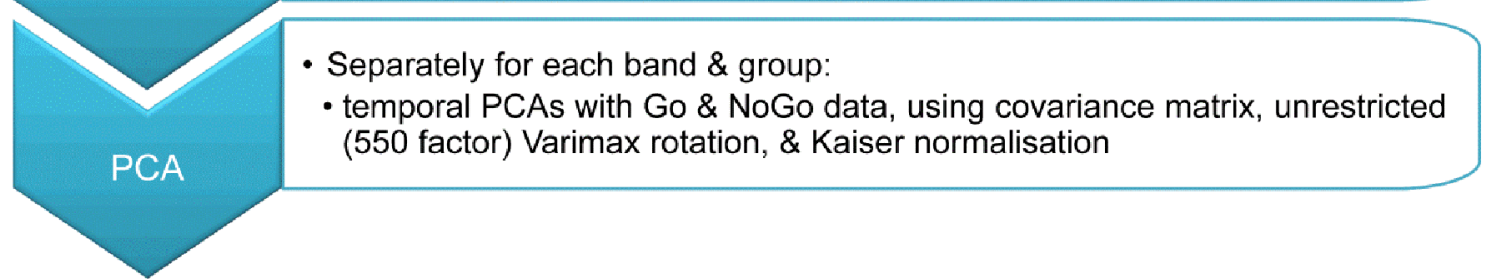

Figure S1. Major quantification steps of the present study. Unless otherwise stated, this protocol was applied separately for each participant group (young, older adults) and stimulus (Go, NoGo). 


\section{S2. Prestimulus EEG contributions from overlapping phase-locked spectra}

Given the fixed 1,100 ms SOA employed in this paradigm, ERP components peaking at or after $600 \mathrm{~ms}$ (such as the LP) directly overlapped the prestimulus period (-500 to $0 \mathrm{~ms}$ ) of the subsequent trial. In order to rule out contributions from this ongoing phase-locked activity to the subsequent prestimulus EEG period, spectra and band amplitude data were also derived for the mean (within-subjects) prestimulus epochs; these are displayed in the left panel of Figure S2. Phase-locked to the end of the preceding trial, these spectral amplitudes (upper left panel) and topographic band distributions (lower left panel), are clearly much reduced relative to the corresponding mean data derived from the individual epochs (right panels; duplicated from manuscript Figure 1); note the use of consistent scales between these data to emphasis this discrepancy. Across all sites and assessed frequencies, phase-locked spectral amplitudes were on average $88.1 \%(73.2-94.1 \%)$ smaller than their non-phase locked counterparts in the young adult data, and $85.7 \%(64.9-94.3 \%)$ smaller in the older adult data. These spectra show a similar peak delta frequency of $\sim 1.5 \mathrm{~Hz}$ across the groups in relation to the non-phase-locked spectra, although here the older adults show a small amplitude increase in the delta frequency range relative to the young, and more so at $\mathrm{Cz}$. Furthermore, a more prominent peak theta frequency of $4 \mathrm{~Hz}$ is evident across the groups in these phase-locked spectra, with the older adults showing only minimal reductions in the theta range. Although not statistically assessed, these data clearly indicate minimal/negligible influence of the preceding and/or overlapping ERP activity. 

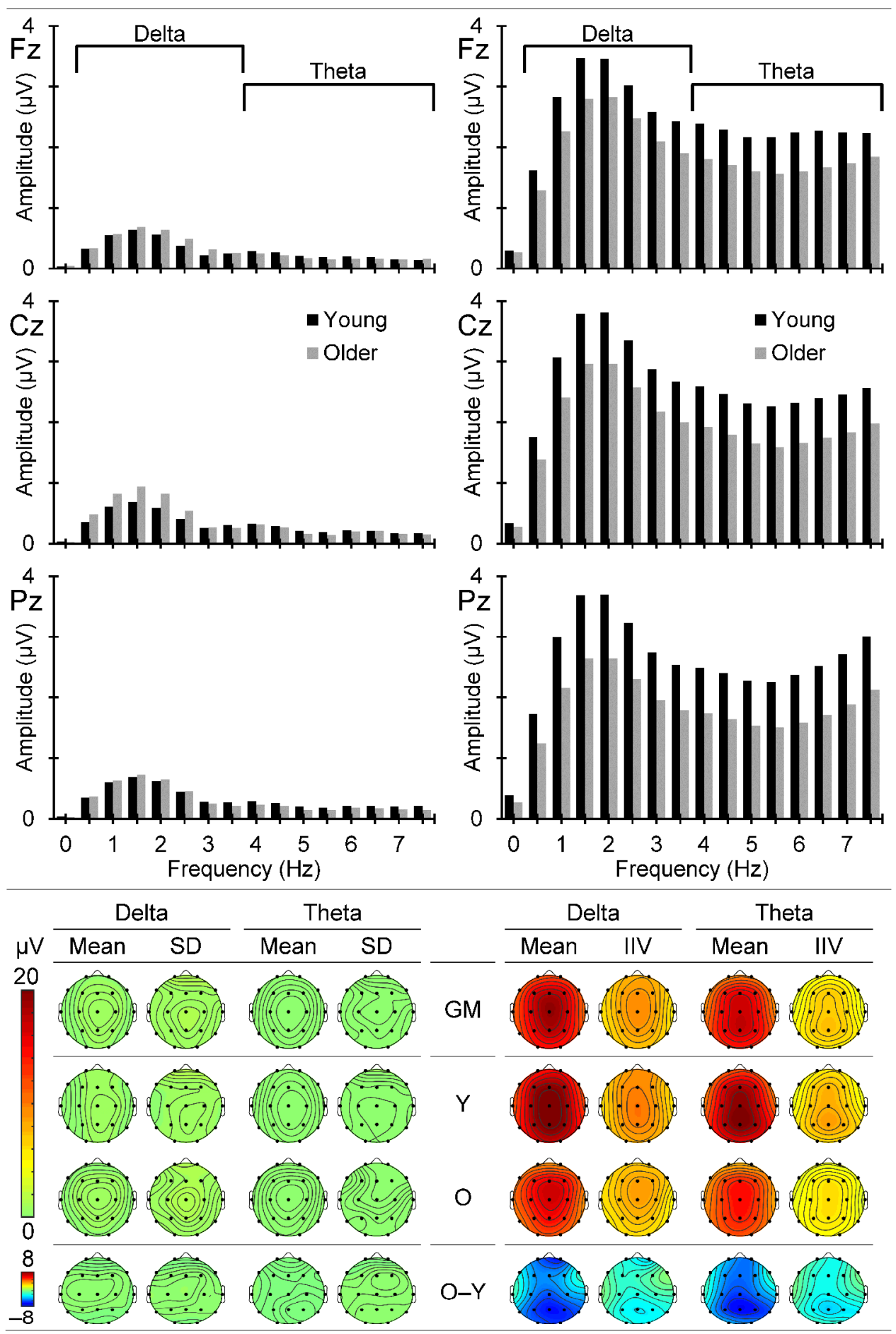

Figure S2. Upper panel: Mean low-frequency prestimulus (-500 to $0 \mathrm{~ms}$ ) EEG spectral amplitudes (acrosssubjects and Go/NoGo) for the young and older adult groups at the midline sites. Phase-locked spectra, derived from the mean (within-subject) prestimulus epochs are displayed on the left, and non-phase-locked spectra, derived from the individual prestimulus epochs are presented on the right. Lower panel: Corresponding delta $(0.5-3.5 \mathrm{~Hz})$ and theta $(4.0-7.5 \mathrm{~Hz})$ band amplitude topographies are presented for the (across-participant) grand mean (GM), separately for the young $(\mathrm{Y})$ and older $(\mathrm{O})$ adult groups, and for the older relative to young adult difference $(\mathrm{O}-\mathrm{Y})$. Mean amplitude and amplitude variability are illustrated for each. Variability is represented by the mean (across-subject) standard deviation (SD) in the phase-locked data, and the mean (within-subject) intra-individual variability (IIV) in the non-phase-locked data. 


\section{S3. Derivation of prestimulus EEG band levels}

Mean prestimulus EEG band amplitudes across the midline region were used to sort the accepted epochs (within-subjects), separately for the delta and theta band sorting conditions. Up to nine epochs were then removed (per participant for each stimulus) in a distributed fashion from their respective sorted datasets to enable even (within-subjects) epoch distribution into the 10 prestimulus EEG band amplitude levels. The 10 prestimulus EEG band level ERPs were then derived for each participant and each stimulus, in each band sorting condition. Table S1 summarises the number of epochs at each of these three processing stages: EEG band amplitude analysis (i.e., total accepted epoch numbers), epoch removal following the prestimulus EEG band amplitude sort, and the number of epochs contributing to each of the 10 prestimulus EEG band level ERPs. Importantly, it should be noted that although the epoch summary information was consistent for the prestimulus delta and theta band sorting conditions, their epoch sorting orders differed, and thus the epochs that were removed, and the epoch groupings forming each average prestimulus EEG band level ERP differed (withinsubjects) according to the sorting band.

Table S1. Epoch summary information; $M(S D)$ number of epochs at three processing stages.

\begin{tabular}{lcccccccc}
\hline & \multicolumn{2}{c}{ Prestimulus EEG analysis } & & \multicolumn{2}{c}{ Removed following band sort } & & \multicolumn{2}{c}{ Contributing to each ERP } \\
\cline { 2 - 3 } \cline { 8 - 9 } Group & Go & NoGo & & Go & NoGo & & Go & NoGo \\
\hline Young & $278.9(7.2)$ & $282.0(14.6)$ & & $3.9(2.7)$ & $5.5(2.9)$ & & $27.5(0.7)$ & $27.7(1.4)$ \\
Older & $273.9(18.4)$ & $280.5(24.8)$ & & $5.4(2.9)$ & $4.5(2.6)$ & & $26.9(1.7)$ & $27.6(2.4)$ \\
\cline { 2 - 3 } Mean & $276.4(14.0)$ & $281.2(20.1)$ & & $4.7(2.9)$ & $5.0(2.8)$ & & $27.2(1.3)$ & $27.6(1.9)$ \\
\hline
\end{tabular}

Separate repeated measures MANOVAs with Stimulus (Go, NoGo) as the within-subjects factor, and Group (young, older adults) as the between-subjects factor revealed no main effect of Group or Group $\times$ Condition interaction for either the total number of accepted epochs (assessed in the prestimulus EEG band analyses) or the number of epochs contributing to the prestimulus EEG band level ERPs (all $p \geq .153$ ). This was not surprising given that the young and older adults showed comparable behavioural performance in this simple task (see Barry et al, 2016a), and few epochs were lost to EOG artifact with the application of the RAAA EOG correction program (Croft \& Barry, 2000). Across the groups, significantly less epochs contributed in Go than NoGo for each of these datasets (EEG, ERP), $F(1,38) \leq 5.41, p \geq .025, \eta_{\mathrm{p}}{ }^{2} \geq .11$; this was not anticipated to adversely influence the study outcomes given the reasonable number of Go epochs contributing to each dataset ( $\geq 221$ Go epochs in the EEG dataset, $\geq 22$ Go epochs in each Go ERP).

\section{S4. PCA component identification and consistency with Barry et al. (2016a)}

Of the 550 factors rotated in each of the prestimulus delta and prestimulus theta sorted ERP PCAs, seven components matching those identified in Barry et al. (2016a) were similarly identified in the young ( $\mathrm{P} 1$, N1-1, Processing Negativity [PN], P2/N2b, P3, Slow Wave [SW], Late Positivity [LP]) and older (P1, N1-1, PN, P2/N2b, P3a, SW, LP) adult datasets; note that the older adult P3a component will hereafter be referred to as P3. Although not assessed here, evidence of an N2c was found in each of the young adult PCAs, as was a small P3b component in the older adult outcomes. 
Tucker's (1951) Coefficient of Congruence $\left(r_{c}\right)$ was used to confirm that the PCA components identified in the prestimulus delta and theta sort conditions corresponded with those reported in Barry et al. (2016a) which were derived from the grand mean ERPs (across all epochs) for these participant samples. This test provides a form of correlation of the unscaled factor loadings, and indicates the similarity between the components based solely on their temporal aspects (i.e., latency: rise, peak, fall; and relative magnitude). Lorenzo-Seva and ten Berge (2006) provide a guide for interpreting this coefficient: $r_{c}>.95$ indicates component equality, $.94 \geq r_{c} \geq .85$ indicates component similarity, and $r_{c}<.85$ indicates no similarity. Go and NoGo amplitudes at each electrode (averaged across participants and prestimulus EEG band levels) were also correlated with those in Barry et al. (2016a) to confirm they matched in terms of topography $(N=38)$.

Figure S3 displays the amplitude distributions (across prestimulus EEG band levels) in the identified components for each sorting band (delta, theta), Group (young, older adults), and Stimulus (Go, NoGo). Component latency data are displayed below these, and also the statistics comparing the young and older adult components with their Barry et al. (2016a) counterparts.

In the prestimulus delta sort, the young components matched those identified in Barry et al. (2016a) both temporally (all $r_{c} \geq .95$ ) and topographically (all $r(36) \geq .97, p<.001$ ). The older adult components also showed high similarity or temporal equivalence (all $r_{c} \geq .94$ ), and topographical comparability (all $r(36) \geq .95, p$ $<.001$ ) with their Barry et al. (2016a) counterparts. In the prestimulus theta sort, each of the young components showed high similarity or temporal equivalence (all $r_{c} \geq .94$ ), and significant topographic consistency (all $r(36)$ $\geq .94, p<.001$ ) with their corresponding Barry et al. (2016a) components. Excluding the P2/N2b complex, the older adult components were temporally similar or equivalent $\left(r_{c} \geq 85\right)$, and topographically consistent (all $r(36) \geq .90, p<.001$ ) with their corresponding Barry et al. (2016a) components. The older adult P2/N2b identified in the prestimulus theta sort peaked $20 \mathrm{~ms}$ earlier than that identified in Barry et al. (2016a), and thus these components were temporally dissimilar according to Lorenzo-Seva and ten Berge's (2006) criteria $\left(r_{c}<\right.$ $.85)$, although they showed topographic consistency $(r(36)=.61, p<.001)$. 


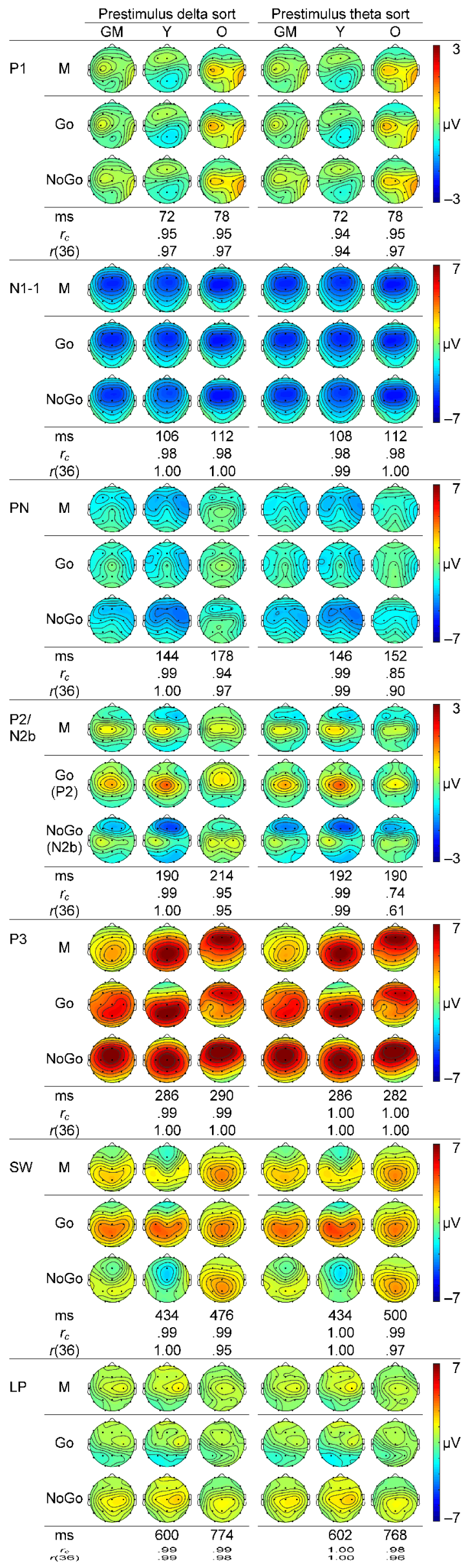

Figure S3. Topographic distributions of identified PCA components, averaged across the 10 prestimulus EEG band levels, in latency order. These are presented for the Young (Y) and older $(\mathrm{O})$ adult groups, and the grand mean across them (GM), each for the separate conditions (Go, NoGo), and their mean (M). Below these are the component peak latencies (ms), and data indicating similarity with the corresponding Barry et al. (2016a) components; the congruence coefficient $\left(r_{c}\right)$ indicates the temporal correspondence, and $\mathrm{r}(36)$ the topographic correspondence. 


\section{S5. Grand mean and Go/NoGo PCA component topography}

For each identified component, the grand mean and Go/NoGo component topography statistics (across the prestimulus EEG band levels and young/older adult groups) are presented in Table S2. It is evident that many of the topographic distributions were similarly present for the components obtained in the prestimulus delta and prestimulus theta sort conditions. In an effort to simplify the reporting of these effects, unless otherwise specified, the following results should be interpreted as applying to components derived from both prestimulus EEG band sort conditions. For each effect, the grand mean (GM) headmaps in Figure S3 should provide a reasonable illustration.

Across Go/NoGo, P1 was a central, particularly central-left, positivity and was relatively reduced in the parietal midline. Go (cf. NoGo) P1 was enhanced in the left hemisphere, more so centrally, and in the central hemispheres. N1-1 was a fronto-central and midline negativity, with a frontal hemispheric increase. This topography did not interact with Go/NoGo.

PN was a central, particularly in the hemispheres, and frontal-midline negativity, with a right hemispheric bias. PN was relatively more frontal in the prestimulus delta (but not the prestimulus theta) sort. When viewing these effects in Figure S3, note that the temporal (cf. hemispheric) sites were assessed for this component; assessed PN sites were F7, Fz, F8, T7, Cz, T8, P7, Pz, and P8. PN was more negative in NoGo than Go generally (across sites), and more so frontally, particularly in the midline. However, Go PN was greater in the hemispheres, particularly centrally, demonstrating the temporal topographic enhancement typical of this component (Näätänen \& Picton, 1987). NoGo PN showed an additional enhancement in the central region in the prestimulus theta sort.

P2/N2b positivity was centrally dominant, and showed a left hemisphere bias across Go/NoGo. Go $\mathrm{P} 2$ positivity was enhanced in the midline, particularly fronto-centrally, and generally (across assessed sites), while the NoGo N2b was frontally negative. In the prestimulus theta sort, Go P2/N2b also showed a relative enhancement in the frontal-left region. Across Go/NoGo, P3 was a central and midline positivity, and showed a central-right increase. Go P3 was enhanced in the right hemisphere, particularly centrally, and in the parietal midline. NoGo P3 was enhanced in the fronto-central regions, in the midline, and at the vertex; these contributed to the overall general enhancement in NoGo.

The SW was a centro-parietal positivity across Go/NoGo, and was increased in the central hemispheres and parietal-midline. The Go SW was enhanced centrally, in the midline, in the parietal midline and parietal left regions, and was generally greater (more positive) than the NoGo SW. The LP was a centrally dominant positivity across Go/NoGo, and was increased in the right hemisphere, in the frontal hemispheres, and in the central-right region. NoGo (cf. Go) LP was enhanced in the parietal region, particularly in the left, and was generally increased across the assessed sites. 
Table S2. Grand mean ERP component topography and Go/NoGo statistics across prestimulus EEG band Level (L01-L10) and Group (young, older adult).

\begin{tabular}{|c|c|c|c|c|c|c|c|}
\hline \multirow[b]{2}{*}{ Component } & \multirow[b]{2}{*}{ Effect } & \multicolumn{3}{|c|}{ Prestimulus delta sort } & \multicolumn{3}{|c|}{ Prestimulus theta sort } \\
\hline & & $F$ & $p$ & $\eta_{\mathrm{p}}^{2}$ & $F$ & $p$ & $\eta_{p}^{2}$ \\
\hline \multirow[t]{6}{*}{ P1 } & $\mathrm{C}>\mathrm{F} / \mathrm{P}$ & 9.31 & .004 & .20 & 9.24 & .004 & .20 \\
\hline & $\mathrm{F}>\mathrm{P} \times \mathrm{M}>\mathrm{L} / \mathrm{R}$ & 13.19 & .001 & .26 & 10.81 & .002 & .22 \\
\hline & $\mathrm{C}>\mathrm{F} / \mathrm{P} \times \mathrm{L}>\mathrm{R}$ & 21.40 & $<.001$ & .36 & 21.75 & $<.001$ & .36 \\
\hline & $\mathrm{G}>\mathrm{N} \times \mathrm{L}>\mathrm{R}$ & 7.90 & .008 & .17 & 5.66 & .022 & .13 \\
\hline & $\mathrm{G}>\mathrm{N} \times \mathrm{C}>\mathrm{F} / \mathrm{P} \times \mathrm{L}>\mathrm{R}$ & 10.68 & .002 & .22 & 10.79 & .002 & .22 \\
\hline & $\mathrm{G}>\mathrm{N} \times \mathrm{C}>\mathrm{F} / \mathrm{P} \times \mathrm{M}<\mathrm{L} / \mathrm{R}$ & 4.20 & .047 & .10 & 5.99 & .019 & .14 \\
\hline \multirow[t]{4}{*}{ N1-1 } & $\mathrm{F}>\mathrm{P}$ & 47.18 & $<.001$ & .55 & 46.01 & $<.001$ & .55 \\
\hline & $\mathrm{C}>\mathrm{F} / \mathrm{P}$ & 50.34 & $<.001$ & .57 & 50.10 & $<.001$ & .57 \\
\hline & $\mathrm{M}>\mathrm{L} / \mathrm{R}$ & 39.46 & $<.001$ & .51 & 40.87 & $<.001$ & .52 \\
\hline & $\mathrm{F}>\mathrm{P} \times \mathrm{M}<\mathrm{L} / \mathrm{R}$ & 24.00 & $<.001$ & .39 & 21.94 & $<.001$ & .37 \\
\hline \multirow[t]{11}{*}{$\mathrm{PN}^{\dagger}$} & $\mathrm{F}>\mathrm{P}$ & 6.11 & .018 & .14 & & & \\
\hline & $\mathrm{C}>\mathrm{F} / \mathrm{P}$ & 4.98 & .032 & .12 & 17.59 & $<.001$ & .32 \\
\hline & $\mathrm{L}<\mathrm{R}$ & 17.63 & $<.001$ & .32 & 22.90 & $<.001$ & .38 \\
\hline & $\mathrm{F}>\mathrm{P} \times \mathrm{M}>\mathrm{L} / \mathrm{R}$ & 7.95 & .008 & .17 & 14.89 & $<.001$ & .28 \\
\hline & $\mathrm{C}>\mathrm{F} / \mathrm{P} \times \mathrm{M}<\mathrm{L} / \mathrm{R}$ & 12.50 & .001 & .25 & 12.58 & .001 & .25 \\
\hline & $\mathrm{G}<\mathrm{N}$ & 22.82 & $<.001$ & .38 & 43.14 & $<.001$ & .53 \\
\hline & $\mathrm{G}<\mathrm{N} \times \mathrm{F}>\mathrm{P}$ & 10.55 & .002 & .22 & 4.56 & .039 & .11 \\
\hline & $\mathrm{G}<\mathrm{N} \times \mathrm{C}>\mathrm{F} / \mathrm{P}$ & & & & 14.78 & $<.001$ & .28 \\
\hline & $\mathrm{G}>\mathrm{N} \times \mathrm{M}<\mathrm{L} / \mathrm{R}$ & 38.84 & $<.001$ & .51 & 60.46 & $<.001$ & .61 \\
\hline & $\mathrm{G}<\mathrm{N} \times \mathrm{F}>\mathrm{P} \times \mathrm{M}>\mathrm{L} / \mathrm{R}$ & 16.12 & $<.001$ & .30 & 6.43 & .015 & .14 \\
\hline & $\mathrm{G}>\mathrm{N} \times \mathrm{C}>\mathrm{F} / \mathrm{P} \times \mathrm{M}<\mathrm{L} / \mathrm{R}$ & 20.55 & $<.001$ & .35 & 13.35 & .001 & .26 \\
\hline \multirow[t]{8}{*}{$\mathrm{P} 2 / \mathrm{N} 2 \mathrm{~b}$} & $\mathrm{C}>\mathrm{F} / \mathrm{P}$ & 23.83 & $<.001$ & .39 & 24.69 & $<.001$ & .39 \\
\hline & $\mathrm{L}>\mathrm{R}$ & 7.48 & .009 & .16 & 6.19 & .017 & .14 \\
\hline & $\mathrm{G}>\mathrm{N}$ & 12.11 & .001 & .24 & 13.82 & .001 & .27 \\
\hline & $\mathrm{G}>\mathrm{N} \times \mathrm{F}>\mathrm{P}$ & 16.84 & $<.001$ & .31 & 11.83 & .001 & .24 \\
\hline & $\mathrm{G}>\mathrm{N} \times \mathrm{M}>\mathrm{L} / \mathrm{R}$ & 42.55 & $<.001$ & .53 & 49.95 & $<.001$ & .57 \\
\hline & $\mathrm{G}>\mathrm{N} \times \mathrm{F}>\mathrm{P} \times \mathrm{L}>\mathrm{R}$ & & & & 8.51 & .006 & .18 \\
\hline & $\mathrm{G}>\mathrm{N} \times \mathrm{F}>\mathrm{P} \times \mathrm{M}>\mathrm{L} / \mathrm{R}$ & 18.29 & $<.001$ & .32 & 21.81 & $<.001$ & .36 \\
\hline & $\mathrm{G}>\mathrm{N} \times \mathrm{C}>\mathrm{F} / \mathrm{P} \times \mathrm{M}>\mathrm{L} / \mathrm{R}$ & 28.31 & $<.001$ & .43 & 34.23 & $<.001$ & .47 \\
\hline
\end{tabular}




\begin{tabular}{|c|c|c|c|c|c|c|c|}
\hline \multirow[b]{2}{*}{ Component } & \multirow[b]{2}{*}{ Effect } & \multicolumn{3}{|c|}{ Prestimulus delta sort } & \multicolumn{3}{|c|}{ Prestimulus theta sort } \\
\hline & & $F$ & $p$ & $\eta_{\mathrm{p}}^{2}$ & $F$ & $p$ & $\eta_{\mathrm{p}}^{2}$ \\
\hline \multirow[t]{11}{*}{ P3 } & $\mathrm{C}>\mathrm{F} / \mathrm{P}$ & 7.61 & .009 & .17 & 7.45 & .010 & .16 \\
\hline & $\mathrm{M}>\mathrm{L} / \mathrm{R}$ & 46.02 & $<.001$ & .55 & 49.82 & $<.001$ & .57 \\
\hline & $\mathrm{C}>\mathrm{F} / \mathrm{P} \times \mathrm{L}<\mathrm{R}$ & 8.43 & .006 & .18 & 8.38 & .006 & .18 \\
\hline & $\mathrm{G}<\mathrm{N}$ & 12.98 & .001 & .25 & 13.95 & .001 & .27 \\
\hline & $\mathrm{G}<\mathrm{N} \times \mathrm{F}>\mathrm{P}$ & 66.96 & $<.001$ & .64 & 62.96 & $<.001$ & .62 \\
\hline & $\mathrm{G}<\mathrm{N} \times \mathrm{C}>\mathrm{F} / \mathrm{P}$ & 24.77 & $<.001$ & .39 & 25.63 & $<.001$ & .40 \\
\hline & $\mathrm{G}>\mathrm{N} \times \mathrm{L}<\mathrm{R}$ & 36.06 & $<.001$ & .49 & 38.34 & $<.001$ & .50 \\
\hline & $\mathrm{G}<\mathrm{N} \times \mathrm{M}>\mathrm{L} / \mathrm{R}$ & 45.98 & $<.001$ & .55 & 47.39 & $<.001$ & .55 \\
\hline & $\mathrm{G}>\mathrm{N} \times \mathrm{F}<\mathrm{P} \times \mathrm{M}>\mathrm{L} / \mathrm{R}$ & 28.81 & $<.001$ & .43 & 26.76 & $<.001$ & .41 \\
\hline & $\mathrm{G}>\mathrm{N} \times \mathrm{C}>\mathrm{F} / \mathrm{P} \times \mathrm{L}<\mathrm{R}$ & 42.68 & $<.001$ & .53 & 45.10 & $<.001$ & .54 \\
\hline & $\mathrm{G}<\mathrm{N} \times \mathrm{C}>\mathrm{F} / \mathrm{P} \times \mathrm{M}>\mathrm{L} / \mathrm{R}$ & 40.20 & $<.001$ & .51 & 40.49 & $<.001$ & .52 \\
\hline \multirow[t]{9}{*}{ SW } & $\mathrm{F}<\mathrm{P}$ & 25.82 & $<.001$ & .40 & 28.95 & $<.001$ & .43 \\
\hline & $\mathrm{C}>\mathrm{F} / \mathrm{P}$ & 9.43 & .004 & .20 & 11.92 & .001 & .24 \\
\hline & $\mathrm{F}<\mathrm{P} \times \mathrm{M}>\mathrm{L} / \mathrm{R}$ & 59.15 & $<.001$ & .61 & 64.17 & $<.001$ & .63 \\
\hline & $\mathrm{C}>\mathrm{F} / \mathrm{P} \times \mathrm{M}<\mathrm{L} / \mathrm{R}$ & 16.53 & $<.001$ & .30 & 15.17 & $<.001$ & .29 \\
\hline & $\mathrm{G}>\mathrm{N}$ & 26.06 & $<.001$ & .41 & 25.60 & $<.001$ & .40 \\
\hline & $\mathrm{G}>\mathrm{N} \times \mathrm{C}>\mathrm{F} / \mathrm{P}$ & 23.55 & $<.001$ & .38 & 24.54 & $<.001$ & .39 \\
\hline & $\mathrm{G}>\mathrm{N} \times \mathrm{M}>\mathrm{L} / \mathrm{R}$ & 7.93 & .008 & .17 & 7.29 & .010 & .16 \\
\hline & $\mathrm{G}>\mathrm{N} \times \mathrm{F}<\mathrm{P} \times \mathrm{L}>\mathrm{R}$ & 18.60 & $<.001$ & .33 & 18.40 & $<.001$ & .33 \\
\hline & $\mathrm{G}>\mathrm{N} \times \mathrm{F}<\mathrm{P} \times \mathrm{M}>\mathrm{L} / \mathrm{R}$ & 19.62 & $<.001$ & .34 & 19.22 & $<.001$ & .34 \\
\hline \multirow[t]{7}{*}{ LP } & $\mathrm{C}>\mathrm{F} / \mathrm{P}$ & 31.11 & $<.001$ & .45 & 26.33 & $<.001$ & .41 \\
\hline & $\mathrm{L}<\mathrm{R}$ & 14.15 & .001 & .27 & 15.93 & $<.001$ & .30 \\
\hline & $\mathrm{F}>\mathrm{P} \times \mathrm{M}<\mathrm{L} / \mathrm{R}$ & 8.21 & .007 & .18 & 7.60 & .009 & .17 \\
\hline & $\mathrm{C}>\mathrm{F} / \mathrm{P} \times \mathrm{L}<\mathrm{R}$ & 10.41 & .003 & .22 & 11.75 & 001 & .24 \\
\hline & $\mathrm{G}<\mathrm{N}$ & 8.94 & .005 & .19 & 10.88 & .002 & .22 \\
\hline & $\mathrm{G}<\mathrm{N} \times \mathrm{F}<\mathrm{P}$ & 16.14 & $<.001$ & .30 & 19.82 & $<.001$ & .34 \\
\hline & $\mathrm{G}<\mathrm{N} \times \mathrm{F}<\mathrm{P} \times \mathrm{L}>\mathrm{R}$ & 8.68 & .005 & .19 & 9.46 & .004 & .20 \\
\hline
\end{tabular}

Notes: ${ }^{\dagger} \mathrm{PN}$ analysis compared the temporal (L/R: F7/F8, T7/T8, P7/P8) and midline (M: Fz, Cz, Pz) sites. $\mathrm{G}=\mathrm{Go} ; \mathrm{N}=\mathrm{NoGo} ; \mathrm{F}=$ frontal; $\mathrm{P}=$ parietal; $\mathrm{C}=$ central; $\mathrm{F} / \mathrm{P}=$ fronto-parietal mean; $\mathrm{L}$

$=$ left hemisphere; $\mathrm{R}=$ right hemisphere; $\mathrm{M}=$ midline; $\mathrm{L} / \mathrm{R}=$ hemispheric mean. 


\section{S6. Age-related change in the additional ERP components}

Group statistics are reported in Table S3, which indicates that these effects were consistent between the prestimulus delta and theta sort conditions. PN was generally reduced (across sites) in the older relative to young adults; this did not differ with Go/NoGo. Across Go/NoGo, the older (cf. young) SW positivity was enhanced in the midline, particularly centrally. However, the young demonstrated greater relative Go (cf. NoGo) enhancements in the central region, left hemisphere, and generally across sites due to the frontal NoGo negativity in this group. The older (cf. young) LP showed reductions in the central hemispheres, particularly in the right; this central-right reduction was greater in Go than NoGo.

Table S3. Group (young, older adult) effects across prestimulus EEG band Level (L01-L10).

\begin{tabular}{|c|c|c|c|c|c|c|c|}
\hline \multirow[b]{2}{*}{ Outcome } & \multirow[b]{2}{*}{ Effect } & \multicolumn{3}{|c|}{ Prestimulus delta sort } & \multicolumn{3}{|c|}{ Prestimulus theta sort } \\
\hline & & $F$ & $p$ & $\eta_{\mathrm{p}}^{2}$ & $F$ & $p$ & $\eta_{\mathrm{p}}^{2}$ \\
\hline $\mathrm{PN}^{\dagger}$ & $\mathrm{Y}>\mathrm{O}$ & 10.52 & .002 & .22 & 7.20 & .011 & .16 \\
\hline \multirow[t]{5}{*}{ SW } & $\mathrm{Y}<\mathrm{O} \times \mathrm{M}>\mathrm{L} / \mathrm{R}$ & 26.92 & $<.001$ & .41 & 26.31 & $<.001$ & .41 \\
\hline & $\mathrm{Y}<\mathrm{O} \times \mathrm{C}>\mathrm{F} / \mathrm{P} \times \mathrm{M}>\mathrm{L} / \mathrm{R}$ & 25.13 & $<.001$ & .40 & 23.85 & $<.001$ & .39 \\
\hline & $\mathrm{Y}>\mathrm{O} \times \mathrm{G}>\mathrm{N}$ & 19.14 & $<.001$ & .33 & 19.04 & $<.001$ & .33 \\
\hline & $\mathrm{Y}>\mathrm{O} \times \mathrm{G}>\mathrm{N} \times \mathrm{C}>\mathrm{F} / \mathrm{P}$ & 9.89 & .003 & .21 & 10.27 & .003 & .21 \\
\hline & $\mathrm{Y}>\mathrm{O} \times \mathrm{G}>\mathrm{N} \times \mathrm{L}>\mathrm{R}$ & 5.03 & .031 & .12 & 5.56 & .024 & .13 \\
\hline \multirow[t]{3}{*}{ LP } & $\mathrm{Y}>\mathrm{O} \times \mathrm{C}>\mathrm{F} / \mathrm{P} \times \mathrm{L}<\mathrm{R}$ & 5.37 & .026 & .12 & 6.43 & .015 & .14 \\
\hline & $\mathrm{Y}>\mathrm{O} \times \mathrm{C}>\mathrm{F} / \mathrm{P} \times \mathrm{M}<\mathrm{L} / \mathrm{R}$ & 8.38 & .006 & .18 & 6.91 & .012 & .15 \\
\hline & $\mathrm{Y}>\mathrm{O} \times \mathrm{G}>\mathrm{N} \times \mathrm{C}>\mathrm{F} / \mathrm{P} \times \mathrm{L}<\mathrm{R}$ & 8.66 & .006 & .19 & 8.89 & .005 & .19 \\
\hline
\end{tabular}

Notes: ${ }^{\dagger} \mathrm{PN}$ analysis compared the temporal (L/R: F7/F8, T7/T8, P7/P8) and midline (M: Fz, $\mathrm{Cz}$,

$\mathrm{Pz}$ ) sites. $\mathrm{Y}=$ young; $\mathrm{O}=$ older; $\mathrm{C}=$ central; $\mathrm{F} / \mathrm{P}=$ fronto-parietal mean; $\mathrm{L}=$ left hemisphere; $\mathrm{R}=$ right hemisphere; $\mathrm{M}=$ midline; $\mathrm{L} / \mathrm{R}=$ hemispheric mean; $\mathrm{G}=\mathrm{Go} ; \mathrm{N}=$ NoGo.

The general PN reduction in the older (cf. young) adults occurred across conditions and was independent of this component's defining temporal negativity, which suggests that the older adults invested more effort in the earlier sensory processing stages (indexed by P1 and N1-1), rather than the subsequent stimulus categorisation (Barry \& De Blasio, 2013, 2015; Barry et al., 2016a, 2018). This result lends further support to the interpretation that the older adult group may have adopted a proactive control strategy in this task; see manuscript section 4.2. for further information. The frontal NoGo SW negativity was absent in the older (cf. young) group as has been previously noted (i.e., Pfefferbaum et al., 1980), and this contributed to relative Go responserelated processing enhancement in the young (cf. older) adults (Barry \& De Blasio, 2013, 2015; Barry et al., 2016a, 2018). NoGo processing termination was indicated by a reduced LP in the older group, supporting the findings of Barry et al. (2016a), particularly in the right central region. When taken together with the increased positivity in the older adult NoGo SW, this could suggest a smaller difference between the NoGo SW and LP in the older adults, and a more efficient reset to the resting state ahead of preparation for the next stimulus occurrence. 


\section{S7. Linear effects of prestimulus EEG band level in the additional ERP components}

Table S4 displays the linear prestimulus EEG band amplitude level statistics for the delta and theta band sorting conditions in relation to the additional PCA derived ERP components falling outside the scope of the primary investigation. The novel assessment of these components, the PN, SW, and LP, is presented here in order to promote future investigation. These components are consistently identified in the equiprobable auditory Go/NoGo task, and are hypothesised to index significant processing stages therein (Barry and De Blasio, 2013, 2015; Barry et al., 2016a, 2018). Effects in these components will be presented and discussed separately for each sorting band in turn.

Table S4. Linear (direct, inverse) effects of prestimulus EEG band Level (L01-L10), with and without Group (young, older adult) effects.

\begin{tabular}{|c|c|c|c|c|c|c|c|}
\hline \multirow[b]{2}{*}{ Outcome } & \multirow[b]{2}{*}{ Effect } & \multicolumn{3}{|c|}{ Prestimulus delta sort } & \multicolumn{3}{|c|}{ Prestimulus theta sort } \\
\hline & & $F$ & $p$ & $\eta_{\mathrm{p}}^{2}$ & $F$ & $p$ & $\eta_{\mathrm{p}}^{2}$ \\
\hline \multirow[t]{5}{*}{$\mathrm{PN}^{\dagger}$} & Inverse $\times \mathrm{L}>\mathrm{R}$ & & & & 7.15 & .011 & .16 \\
\hline & Inverse $\times \mathrm{G}>\mathrm{N} \times \mathrm{C}>\mathrm{F} / \mathrm{P}$ & 7.52 & .009 & .17 & & & \\
\hline & Inverse $\times \mathrm{Y}>\mathrm{O} \times \mathrm{F}>\mathrm{P} \times \mathrm{L}<\mathrm{R}$ & 6.27 & .017 & .14 & & & \\
\hline & Inverse $\times \mathrm{Y}>\mathrm{O} \times \mathrm{G}<\mathrm{N} \times \mathrm{F}>\mathrm{P}$ & 8.65 & .006 & .19 & & & \\
\hline & Inverse $\times \mathrm{Y}>\mathrm{O} \times \mathrm{G}>\mathrm{N} \times \mathrm{C}>\mathrm{F} / \mathrm{P} \times \mathrm{M}<\mathrm{L} / \mathrm{R}$ & & & & 6.28 & .017 & .14 \\
\hline \multirow[t]{10}{*}{ SW } & Direct & 9.84 & .003 & .21 & & & \\
\hline & Direct $\times \mathrm{F}>\mathrm{P}$ & 22.33 & $<.001$ & .37 & 13.54 & .001 & .26 \\
\hline & Direct $\times \mathrm{M}<\mathrm{L} / \mathrm{R}$ & & & & 7.39 & .010 & .16 \\
\hline & Direct $\times \mathrm{F}<\mathrm{P} \times \mathrm{L}>\mathrm{R}$ & & & & 6.53 & .015 & .15 \\
\hline & Direct $\times \mathrm{G}>\mathrm{N} \times \mathrm{F}>\mathrm{P}$ & & & & 7.58 & .009 & .17 \\
\hline & Direct $\times \mathrm{G}>\mathrm{N} \times \mathrm{C}<\mathrm{F} / \mathrm{P}$ & 8.67 & .006 & .19 & & & \\
\hline & Direct $\times \mathrm{G}>\mathrm{N} \times \mathrm{M}<\mathrm{L} / \mathrm{R}$ & 8.31 & .006 & .18 & & & \\
\hline & Direct $\times \mathrm{Y}<\mathrm{O}$ & 6.28 & .017 & .14 & & & \\
\hline & Direct $\times \mathrm{Y}<\mathrm{O} \times \mathrm{F}<\mathrm{P} \times \mathrm{L}>\mathrm{R}$ & 7.98 & .007 & .17 & 4.88 & .033 & .11 \\
\hline & Direct $\times \mathrm{Y}<\mathrm{O} \times \mathrm{G}>\mathrm{N} \times \mathrm{F}<\mathrm{P} \times \mathrm{L}>\mathrm{R}$ & & & & 6.81 & .013 & .15 \\
\hline \multirow[t]{6}{*}{ LP } & Direct & 14.08 & .001 & .27 & 7.38 & .010 & .16 \\
\hline & Direct $\times F>P$ & 13.74 & .001 & .27 & 11.17 & .002 & .23 \\
\hline & Direct $\times \mathrm{C}>\mathrm{F} / \mathrm{P}$ & 26.44 & $<.001$ & .41 & 6.00 & .019 & .14 \\
\hline & Direct $\times \mathrm{M}>\mathrm{L} / \mathrm{R}$ & 8.81 & .005 & .19 & & & \\
\hline & Direct $\times \mathrm{C}>\mathrm{F} / \mathrm{P} \times \mathrm{M}>\mathrm{L} / \mathrm{R}$ & 5.76 & .021 & .13 & & & \\
\hline & Direct $\times \mathrm{Y}>\mathrm{O} \times \mathrm{M}>\mathrm{L} / \mathrm{R}$ & & & & 5.82 & .021 & .13 \\
\hline \multicolumn{8}{|c|}{ Notes: ${ }^{\dagger} \mathrm{PN}$ analysis compared the temporal (L/R: F7/F8, T7/T8, P7/P8) and midline (M: Fz, Cz, Pz) sites. } \\
\hline \multicolumn{8}{|c|}{$\begin{array}{l}\mathrm{F}=\text { frontal; } \mathrm{P}=\text { parietal; } \mathrm{C}=\text { central } ; \mathrm{F} / \mathrm{P}=\text { fronto-parietal mean; } \mathrm{L}=\text { left hemisphere; } \mathrm{R}=\text { right } \\
\text { hemisphere; } \mathrm{M}=\text { midline; } \mathrm{L} / \mathrm{R}=\text { hemispheric mean; } \mathrm{G}=\mathrm{Go} ; \mathrm{N}=\text { NoGo; } \mathrm{Y}=\text { young; } \mathrm{O}=\text { older; } \mathrm{RT} \text { (IIV) }\end{array}$} \\
\hline
\end{tabular}




\section{S7.1. Prestimulus delta level}

\section{S7.1.1. $P N$}

With increasing prestimulus delta level, Go (cf. NoGo) PN showed a central reduction across the young and older groups (an inverse linear trend); this and other significant effects of prestimulus delta level are indicated in Figure S4 which presents ERP component topographies for the mean low (L01L03), mid (L04-L07), and high (L08-L10) prestimulus delta levels. Across Go/NoGo, the relative frontal-right elevation in the young (cf. older) adults reduced (an inverse linear trend), while the relative frontal NoGo PN enhancement reduced in the young (an inverse linear trend), but increased in the older adults.

Despite prestimulus delta level's direct and focal modulation of the positivity of this component, which differed by Go/NoGo and Group, it is unlikely to have had a meaningful impact on the associated sensory and stimulus categorisation processes (Barry \& De Blasio, 2013, 2015; Barry et al., 2016a, 2018) given that PN's defining temporal topography (Näätänen \& Picton, 1987) was unaffected.

\section{S7.1.2. $S W$}

Across Group, increased prestimulus delta level was associated with both general (across site) and frontal increases in mean SW amplitude (across Go/NoGo), and with hemispheric and fronto-parietal increases in Go compared to NoGo; all were direct linear trends. The direct linear relationship between prestimulus delta level and SW amplitude was prominent in the older (cf. young) adults globally (across sites), and in the parietal-left region.

Lower prestimulus delta levels therefore appear to be associated with reduced (perhaps more efficient) stimulus-specific processing as indicated by the more well defined Go SW amplitude, and this was consistent for the young and older adults. Some change was seen across the life-span, however, these Group effects failed to differ with Go/NoGo and are thus considered inconsequential here due to the proposed involvement of the SW in only Go (cf. NoGo) processing in this paradigm (Barry \& De Blasio, 2013, 2015; Barry et al., 2016a, 2018).

\section{S7.1.3. LP}

With increased prestimulus delta level, the LP showed general (across sites), fronto-central, midline, and vertex enhancement; these direct linear trends were found across Go/NoGo and Group.

The direct modulation of the positivity in this component, consistent across the young and older adult groups, may reflect an association between lower prestimulus delta level and more efficient stimulus-specific processing. However, the LP is posited as an index of NoGo cortical deactivation in this task (Barry \& De Blasio, 2013, 2015; Barry et al., 2016a, 2018), and as this effect failed to differ by Go/NoGo it is considered to have had little if any impact on the processing outcomes. 


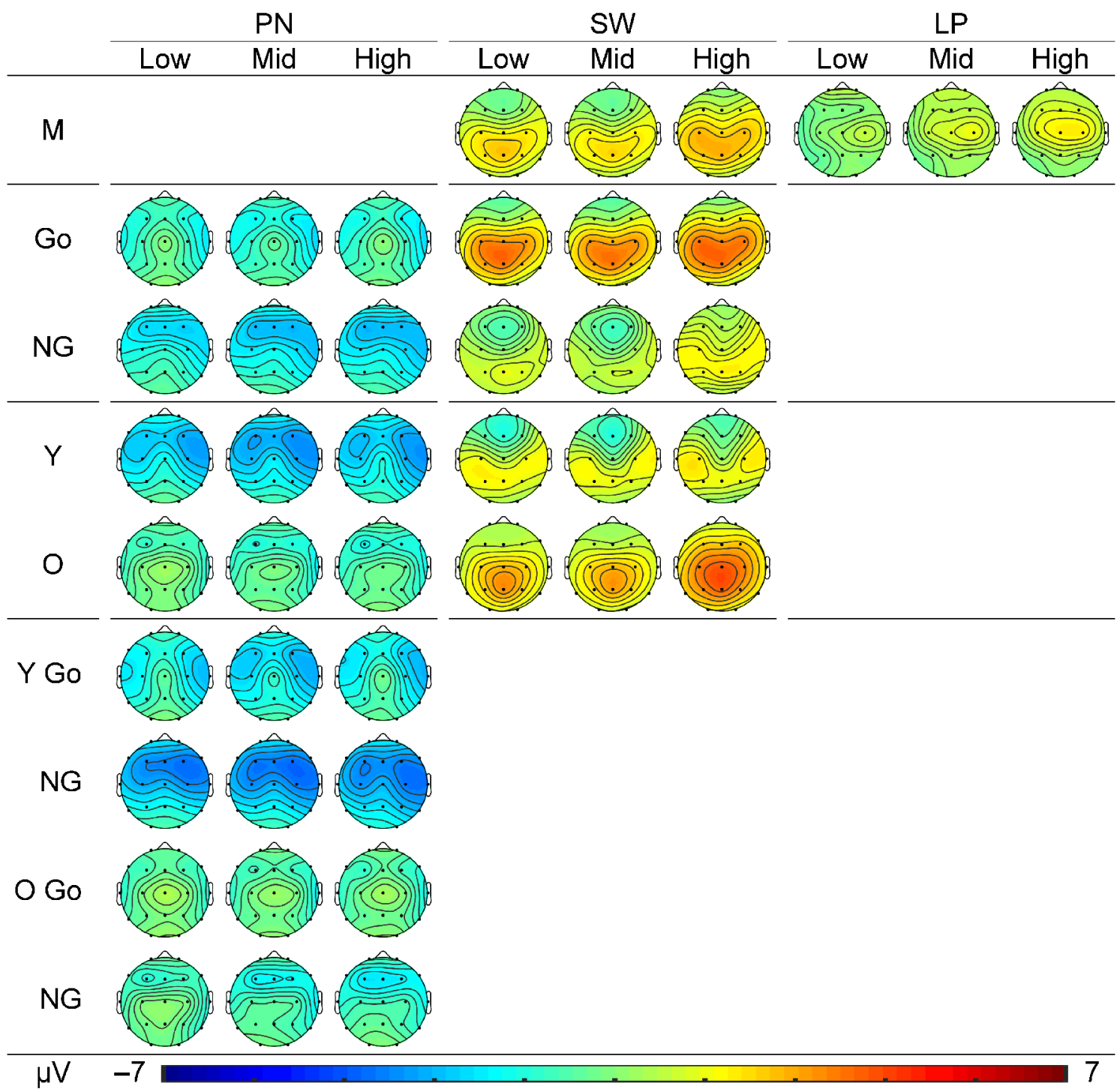

Figure S4. Topographic headmaps illustrating significant prestimulus delta level effects in the PN, SW and LP components. Mean data are presented for Low (mean L01-L03), Mid (mean L04-L07), and High (mean L08-L10) prestimulus delta levels. Note that the PN analysis involved the temporal (cf. hemispheric) sites. $\mathrm{M}=$ mean across $\mathrm{Go} / \mathrm{NoGo}$ and Group; $\mathrm{NG}=\mathrm{NoGo} ; \mathrm{Y}=$ young; $\mathrm{O}=$ older.

\section{S7.2. Prestimulus theta level}

\section{S7.2.1. $P N$}

Increased prestimulus theta level was associated with PN reductions in the left hemispheric region across Go/NoGo and Group (an inverse linear trend), and in the relative temporal Go enhancement for the young (cf. older) adults (an inverse linear trend). These effects are indicated in Figure S5 which presents ERP component topographies for the mean low (L01-L03), mid (L04-L07), and high (L08-L10) prestimulus theta levels to illustrate significant effects of prestimulus activity in this band on the ERP component outcomes.

Across the groups, prestimulus theta level modulated PN amplitude outside of its core topography (i.e., in non-temporal regions), and is therefore considered to have had little if any impact on the associated processing. However, the defining temporal Go PN topography (Näätänen \& Picton, 1987) 
was inversely modulated in the young adults while the older adults showed a more direct modulation, indicating that the prestimulus theta brain state differentially enhances the later stages of sensory processing and stimulus categorisation (Barry \& De Blasio, 2013, 2015; Barry et al., 2016a, 2018) across the lifespan.

\section{S7.2.2. $S W$}

Across Go/NoGo and Group, higher prestimulus theta levels were associated with relative SW increases in the frontal, hemispheric, and parietal-left regions (direct linear trends). The direct linear relationship between prestimulus theta and frontal SW was greater in Go than NoGo across the groups. Across $\mathrm{Go} / \mathrm{NoGo}$, the direct modulation of the parietal-left SW was present in the older adults, while the young showed little evidence of this effect, and in Go (cf. NoGo), this relative parietal-left SW elevation increased in the older adults (a direct linear trend), but reduced in the young.

Across the groups, the prestimulus theta brain state was associated with focal (frontal) Go SW modulation, however, this is likely to have had little effect on the associated processing considering it occurred outside of this component's core (centro-parietal) topography (refer to section S5. above). Prestimulus theta directly modulated parietal left Go SW amplitude in the older but not young adults; this is considered to have produced a meaningful stimulus-specific modulation given its localisation. The functional specificity of the SW component is yet to be fully elucidated in this task, and is currently associated broadly with response preparation and execution (Barry \& De Blasio, 2013, 2015; Barry et al., 2016a, 2018). In the wider literature, however, the positive SW has been hypothesised to index one or more paradigm-specific cognitive process/es that follow target detection and mark task completion (García-Larrea \& Cézanne-Bert, 1998). Consistent with this premise, the SW peaked after the Go response, and may therefore index a separate post-response process, possibly related to response evaluation (i.e., accuracy) or cessation of Go stimulus processing; this interpretation requires further investigation. This result also suggests that prestimulus theta modulates the associated process/es differentially according to age, although this age-related inconsistency may also reflect differential strategy adoption between the young and older adults. Future research should attempt to disentangle such influences and better identify the process/es indexed by this component.

\section{S7.2.3. $L P$}

With increasing prestimulus theta level, the LP increased in the frontal and central regions, and generally across sites; these direct linear trends were found across Go/NoGo and Group. In the young, the LP showed a relative midline increase (a direct linear trend), while the older adults showed a relative reduction.

These LP enhancements were found here across Go/NoGo, despite this being posited as an index of NoGo-specific cortical deactivation following the NoGo non-response (Barry \& De Blasio, 2013, 2015; Barry et al., 2016a, 2018). It is therefore considered unlikely that these effects of prestimulus theta will have influenced the associated processes in this task. 


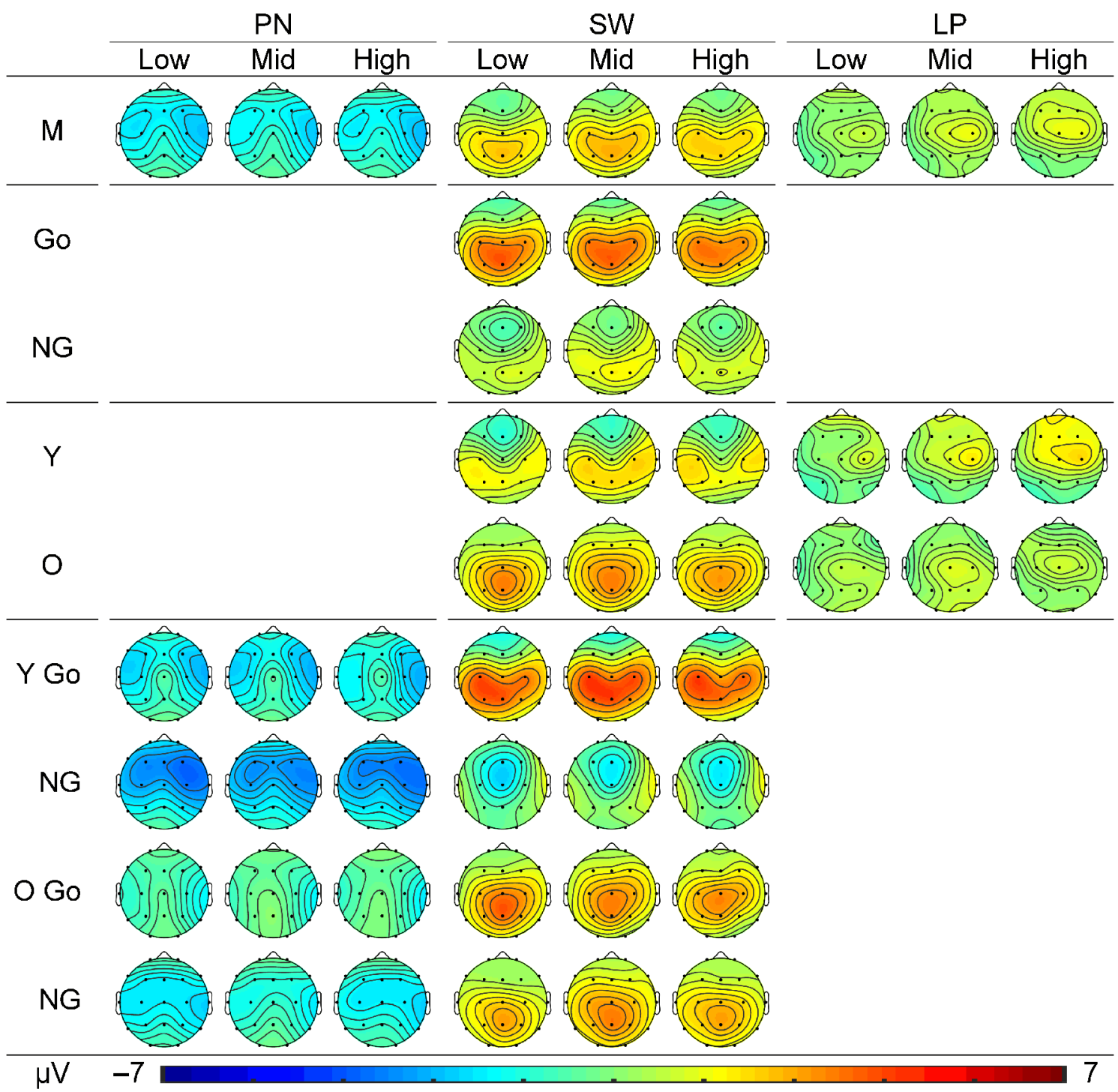

Figure S5. Topographic headmaps illustrating significant prestimulus theta level effects in the PN, SW and LP components. Mean data are presented for Low (mean L01-L03), Mid (mean L04-L07), and High (mean L08-L10) prestimulus theta levels. 


\section{Supplementary References}

Barry, R.J., De Blasio, F.M., 2013. Sequential processing in the equiprobable auditory Go/NoGo task: A temporal PCA study. Int. J. Psychophysiol. 89, 123-127. doi: 10.1016/j.ijpsycho.2013.06.012

Barry, R.J., De Blasio, F.M., 2015. Performance and ERP components in the equiprobable go/no-go task: Inhibition in children. Psychophysiology 52, 1228-1237. doi: 10.1111/psyp.12447

Barry, R.J., De Blasio, F.M., Cave, A.E., 2016a. Sequential processing in young and older adults in the equiprobable auditory Go/NoGo task. Clin. Neurophysiol. 127, 2273-2285. doi: 10.1016/j.clinph.2016.02.010

Barry, R.J., De Blasio, F.M., Fogarty, J.S., 2018. A processing schema for children in the auditory equiprobable Go/NoGo task: ERP components and behaviour. Int. J. Psychophysiol. 123, 74-79. doi: $10.1016 /$ j.ijpsycho.2017.10.014

Croft, R.J., Barry, R.J., 2000. EOG correction of blinks with saccade coefficients: A test and revision of the aligned-artifact average solution. Clin. Neurophysiol. 111, 444-451. doi: 10.1016/S13882457(99)00296-5

García-Larrea, L., Cézanne-Bert, G., 1998. P3, positive slow wave and working memory load: A study on the functional correlates of slow wave activity. Electroen. Clin. Neuro. 108, 260-273. doi: 10.1016/S0168-5597(97)00085-3

Lorenzo-Seva, U., ten Berge, J.M.F., 2006. Tucker's congruence coefficient as a meaningful index of factor similarity. Methodology-EUR 2, 57-64. doi: 10.1027/1614-1881.2.2.57

Näätänen, R., Picton, T., 1987. The N1 wave of the human electric and magnetic response to sound: A review and an analysis of the component structure. Psychophysiology 24, 375-425. doi: 10.1111/j.1469-8986.1987.tb00311.x

Tucker, L.R., 1951. A method for synthesis of factor analysis studies (Personnel Research Section Report No. 984), Department of the Army, Washington, D.C. 